\title{
Effect of sodium fluoride on the grey matter of spinal cord in the albino rat and the protective role of green tea extract
}

\author{
Doaa M. Abo El-Khair, Fatma El-Nabawia A. El-Safti, Mostafa M. El-Habeby, \\ Wael B. El-Kholy, Neveen M. El-Sherif \\ Department of Anatomy and Embryology, Faculty of Medicine, Menoufia University, Al Minufiyah, Egypt
}

\begin{abstract}
Objectives: Fluoride is a toxic and reactive element. Human beings are exposed to fluoride from various sources such as toothpastes, mouth rinses, dietary supplements and ordinary drinking water. This work investigated the effect of sodium fluoride (NaF), alone or with green tea, on the grey matter of spinal cord of adult male albino rats.

Methods: Spinal cord sections were examined using light and electron microscopy. Immunohistochemical assessments for the expression of caspase-3 and glial fibrillary acidic protein were performed. Agarose gel electrophoresis was used for DNA fragmentation.

Results: Our results showed that NaF produced neurodegeneration, vacuolation and haemorrhage with some abnormal blood vessels and a significant increase in the number and size of astrocytes. In addition, the neurons showed a significant decrease of their Nissl's granules content and significant increased expression of caspase-3.

Conclusion: Green tea exerted a protective effect against NaF-induced neurotoxicity. The results of this work add to the known toxic effects of $\mathrm{NaF}$ and provide a new insight into the possible use of green tea to ameliorate these effects.
\end{abstract}

Keywords: fluoride; gel electrophoresis; green tea; histopathology; immunohistochemistry; spinal cord

Anatomy 2016;10(2):114-133 @2016 Turkish Society of Anatomy and Clinical Anatomy (TSACA)

\section{Introduction}

Fluoride is a toxic and reactive element. Human beings are exposed to fluoride from various sources such as toothpastes, mouth rinses, dietary supplements and polymeric surfaces of fluoride in non-stick pans. A significant proportion of $\mathrm{F}$ in the body comes from the consumption of foods with high fluoride natural input such as fish of sea, meat, eggs, fruits and cereal. However, the main source of intake of this element is ordinary drinking water which contributes to more than $60 \%$ of the total fluoride intake. ${ }^{[1]}$

Fluoride, in trace concentrations, is required to prevent dental caries, while the long term consumption of excess fluoride leads to a spectrum of toxic manifestations which are referred to as fluorosis. Fluoride has been shown to be toxic, not only to the skeletal tissues, but also to the non-skeletal tissues such as the brain, liver, pancreas, endocrines and kidney. ${ }^{[2]}$

Fluoride can cross the blood brain barrier and cause adverse effects on the brain cell metabolism, enzymes, oxidant-antioxidant status and on neurotransmitters, and overall adverse effects on mental functions. ${ }^{[3,4]}$ Fluoride also causes morphological changes in various sub-regions of the brain such as significant neurodegenerative changes in the hippocampus, amygdala, motor cortex and cerebellum. ${ }^{[5]}$

Spittle ${ }^{[6]}$ stated that, among the symptoms of chronic fluoride toxicity are muscle spasms, involuntary twitching and tingling sensations in the feet and the fingers which may indicate a spinal cord effect. Epidemiological human and recent animal data suggest that green tea drinking (enriched in a class of flavonoids named catechins) may help protecting the brain. Several studies on the neuro- 
protective and neuroregenerative effects of green tea catechins revealed that they act not only as antioxidants and metal chelators, but also as modulators of intracellular neuronal signaling and metabolism, cell survival/death genes, and mitochondrial function. Thus, these dietary compounds are receiving considerable attention as multifunctional cytoprotective agents that simultaneously manipulate various brain targets. ${ }^{[7]}$

Most of the previous studies were concerned with the effect of fluoride on the brain and the cerebellum. However, the effect of fluoride on the spinal cord is far from clear. It was therefore worthwhile to examine the effect of fluoride on the spinal cord and to examine the possible protective role of green tea.

\section{Materials and Methods}

Twenty-four adult male albino rats (with average weight of 200 grams) obtained from Helwan animal house in Egypt were used in this study. The rats were kept in cages with strict care and hygiene, at room temperature and standard laboratory chow and water ad libitum. The procedure was approved by the ethics committee on animal experiment of the Faculty of Medicine, Menoufia University in accordance with the international regulations on care and use of laboratory animals.

The animals were randomly divided into three groups: Group I (control group) consisted of twelve rats. They were further subdivided into two subgroups: Subgroup Ia (negative control subgroup) consisted of six rats that received distilled water at a dose of $2.4 \mathrm{ml} / \mathrm{rat} /$ day, daily for four weeks orally by gastric intubation. Subgroup Ib (positive control green tea) subgroup consisted of six rats that received green tea extract at a dose of $10 \mathrm{mg} / \mathrm{kg} /$ day, daily for four weeks orally by gastric intubation. ${ }^{[8]}$ Group II consisted of six rats that received sodium fluoride $(\mathrm{NaF})$ at a dose of 12 $\mathrm{mg} / \mathrm{kg} /$ day (NaF-treated group), daily for four weeks orally by gastric intubation. ${ }^{[9]}$ Group III ( $\mathrm{NaF}+$ green tea group protected group) consisted of six rats that received green tea extract 30 minutes before the administration of $\mathrm{NaF}$ at the same doses and duration as the previous groups.

Sodium fluoride was obtained from El-Gomhoria chemical company as white powder. Stock solutions of $\mathrm{NaF}$ were prepared by dissolving $100 \mathrm{mg}$ of $\mathrm{NaF}$ in $100 \mathrm{ml}$ distilled water, to obtain a solution containing $1 \mathrm{mg} \mathrm{NaF} / 1 \mathrm{ml}$ distilled water. Green tea extract was obtained from ElObour Company (El Obour City, Egypt) for modern pharmaceutical industries, in the form of tablets. Each tablet contained $200 \mathrm{mg}$ of green tea extract. Stock solutions of green tea extract were prepared by dissolving $200 \mathrm{mg}$ of green tea extract in $200 \mathrm{ml}$ distilled water, to obtain a solution containing $1 \mathrm{mg}$ green tea extract/1 $\mathrm{ml}$ distilled water.
All rats were weighed at the start and the end of the experiment. The percent of change in the body weight was calculated using the following formula: ${ }^{[10]}$

Percent of change in weight=(W2-W1) $\times 100 / W 1$

$\mathrm{W} 1=$ Weight at the beginning of experiment.

$\mathrm{W} 2=\mathrm{Weight}$ at the end of experiment.

Negative results indicate reduction and positive results indicate increase in weight.

\section{Light microscopy}

At the end of the experiment, all rats were anaesthetized by diethyl ether inhalation. Then, the spinal cord was dissected by clearing away the muscles surrounding the vertebral column and separating the head from the body at the articulations between the skull and the atlas. The spinal cord was carefully exposed throughout its length by removing the roof of each neural (vertebral) arch; then, the cord was removed from the neural (spinal) canal. The cervical and lumbar enlargements of the cord are observed in the cervical and lumbar regions, respectively (Figure 1). ${ }^{[1]}$

The cervical and thoracic parts of the spinal cord were extracted and preserved in $10 \%$ neutral buffered formaldehyde for 24 hours. ${ }^{[12]}$ The specimens were dehydrated in ascending grades of alcohol and xylol was used as a clearing agent. Impregnation was done in pure soft paraffin for two hours at $55^{\circ} \mathrm{C}$ followed by embedding in hard paraffin. Sections of $3-5 \mu \mathrm{m}$ thick were cut by microtome from these paraffine blocks and stained by haematoxylin and eosin $(\mathrm{H} \& \mathrm{E})$ stain for routine histological examination, ${ }^{[13]}$ silver stain for argyrophilic cells, ${ }^{[14]}$ and toluidine blue (TB) stain for Nissl's granules. ${ }^{[13]}$ Immunohistochemical staining for caspase-3 as a marker for apoptosis expressed in the cytoplasm and nucleus was performed using mouse mon-

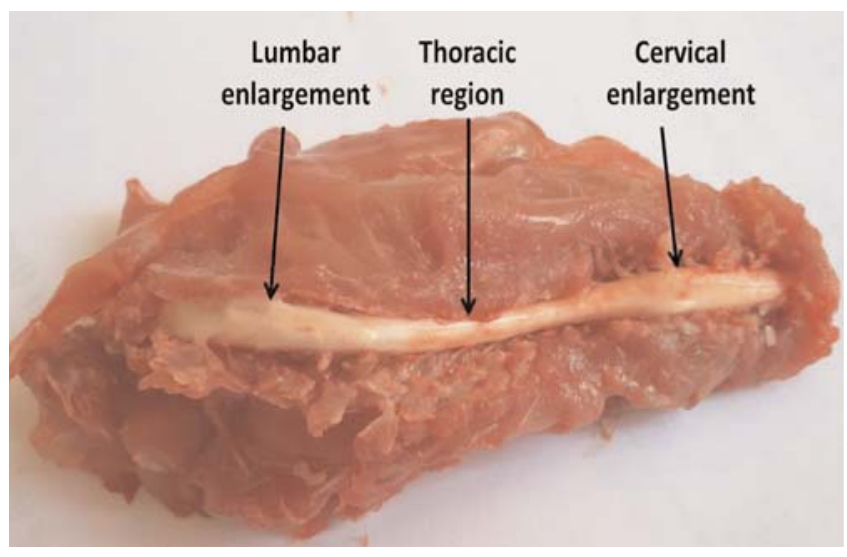

Figure 1. Exposure of the spinal cord inside the vertebral column. [Color figure can be viewed in the online issue, which is available at www.anatomy.org.tr] 
oclonal caspase-3 antibody ${ }^{[15]}$ (Midco Trade Company, Giza, Egypt), and glial fibrillary acidic protein (GFAP) as a marker for gliosis expressed in the cytoplasm of astrocytes using rabbit polyclonal GFAP antibody (Midco Trade Company, Giza, Egypt) were performed. ${ }^{[16]}$

\section{Electron microscopy}

Small parts of both cervical and thoracic segments of the spinal cord were taken and immediately immersed in buffered formol gluteraldehyde $(\mathrm{pH}=7.3)$. After an hour, the cervical and thoracic segments were cut into about 1 $\mathrm{mm}^{3}$ specimens and fixed in buffered formol gluteraldehyde, $\mathrm{pH} 7.3$, for 24 hours at $4{ }^{\circ} \mathrm{C}$ and routinely osmicated in $1 \%$ osmium tetroxide. After dehydration with graded ethanol series, the samples were embedded in Araldite (Huntsman Advanced Materials, Salt Lake City, UT, USA). Then, semithin sections were stained with TB stain as a preliminary step for selection of the areas needed for ultrathin examination. Ultrathin sections were stained with lead citrate and uranyl acetate and were viewed under transmission electron microscope. This was performed in electron microscopy unit of Tanta University, Faculty of Medicine, Tanta, Gharbia Governorate, Egypt.

\section{Morphometric assessment}

Five different stained sections of ventral horn of the spinal cord from five different rats were analyzed using Image J Version 1.47 for Windows (National Institutes of Health, Bethesda, MD, USA) software to measure the following parameters: (a) the number of astrocytes in H\&E-stained sections, ${ }^{[17]}$ (b) the color intensity of Nissl's granules in motor neurons in TB-stained sections, ${ }^{[17]}$ (c) the percent area of astrocytes in GFAP immunostained sections. ${ }^{[18]}$

\section{Agarose gel electrophoresis}

Agarose gel electrophoresis detects DNA fragmentation. This study was performed in the Animal Department of Faculty of Sciences, Menoufia University, Al Minufiyah, Egypt.

\section{Statistical analysis}

Results were collected, tabulated and statistically analyzed using IBM personal computer and statistical package SPSS version 2.0 (SPSS Inc., Chicago, IL, U.S.A). Two types of statistics were done: Descriptive statistics: i.e. mean (X) and standard deviation (SD), and an analytic statistics. As the samples were small, the following non-parametric tests were performed: Paired t-test for dependent groups and Mann-Whitney $U$ test for independent groups. $\mathrm{p} \leq 0.05$ was considered as statistically significant. ${ }^{[19]}$

\section{Results}

\section{The body weight of the animals}

The animals of the negative control subgroup "Subgroup Ia" showed a significant increase in the body weight at the end of the experiment as compared to their weight at the beginning of the experiment. The animals of the positive control subgroup "Subgroup Ib", treated group "Group II" and protected group "Group III" showed a significant decrease in the body weight at the end of the experiment. However, the percent of decrease in the body weight of the protected group was higher than the percent of decrease in the body weight of both positive control subgroup and treated group (Figure 2).

On correlating the different results of different control subgroups, we found that negative (Ia) and positive (Ib) control subgroups showed non-significant difference in different parameters. So, the negative control subgroup (Ia) was considered as the reference control group

\section{Histological findings for the cervical spinal cord Light microscopy findings}

In H\&E-stained sections, the transverse section of cervical spinal cord of the control group was observed as an outer light white matter and an inner dark grey matter. The H-shaped grey matter was divided into ventral and dorsal horns (Figure 3a). The ventral horn showed a moderate number of large basophilic multipolar motor neurons, while the dorsal horn showed a large number of small sensory interneurons. Each neuron in both the ventral and dorsal horns had a central nucleus with a prominent nucleolus. Some cells had long processes (Figures $\mathbf{3 b}-\mathbf{d})$. The neurons were scattered inside eosinophilic neuropil matrix. Inside the neuropil there were few small thin walled blood vessels (Figure 3d) and few astrocytes with small vesicular nuclei (Figures $\mathbf{3 b} \mathbf{b}-\mathbf{d}$ ). The transverse section of the cervical spinal cord of the $\mathrm{NaF}$-treated group showed various degrees of neurodegeneration in

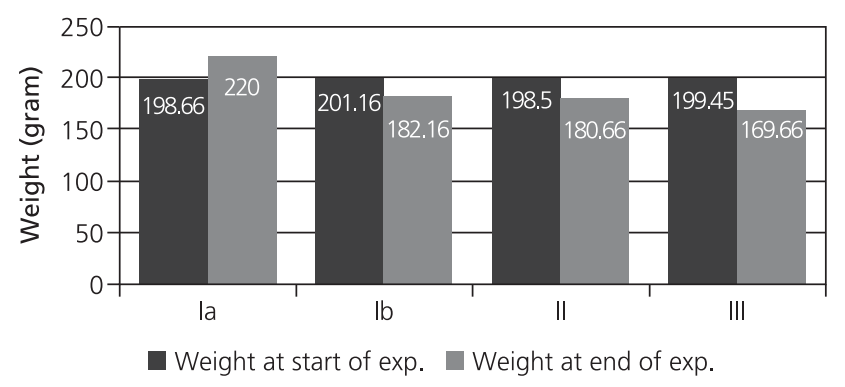

Figure 2. Mean body weight of rats (in grams) at the start and end of the experiment. 

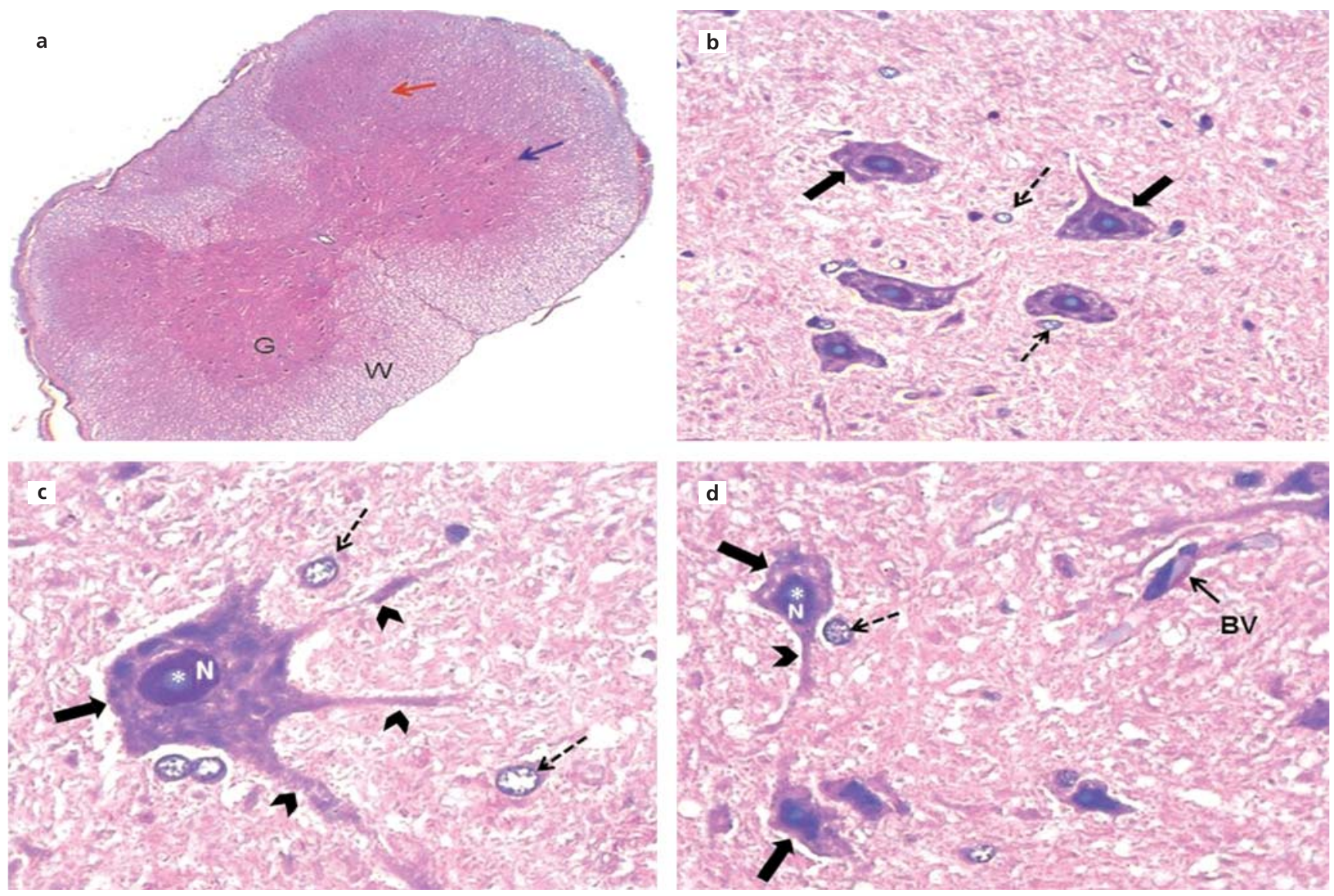

Figure 3. Photomicrographs of transverse sections in the cervical spinal cord of control rats (a) showing outer white matter (W) and inner grey matter (G) which is divided into dorsal horn (red arrow) and ventral horn (blue arrow) (H\&E, $\times 40)$. (b) Ventral horn showing large multipolar motor neurons (thick arrows) and few astrocytes (dashed arrows) (H\&E, x400). (c) Higher magnification of the ventral horn showing a large multipolar motor neuron (thick arrow) with a central nucleus $(\mathrm{N})$ with a prominent nucleolus (*). The cell has long dendrites (arrowheads). Few astrocytes (dashed arrows) are observed in the neuropil. (H\&E, x1000). (d) Higher magnification of the dorsal horn showing small sensory interneurons (thick arrows). Each has a central nucleus $(\mathrm{N})$ with a prominent nucleolus (*). Some have long processes (arrowhead). Few astrocytes (dashed arrow) and a small thin walled blood vessel (BV) could be observed (H\&E, $\times 1000)$. [Color figure can be viewed in the online issue, which is available at www.anatomy.org.tr]

both the ventral and dorsal horns. Many cells were shrunken with dark cytoplasm and loss of nuclear details. Some of these cells were surrounded by vacuolated neuropil. Other cells showed central chromatolysis - "cytoplasmic hyalinization". Few cells appeared as ghost-like cells (Figures 4a-d). The neuropil of both the ventral and dorsal horns showed some areas of vacuolation and many abnormal blood vessels. Some of these blood vessels had distorted endothelium while others were dilated and congested. Moreover, the neuropil showed a significant increase in the number of astrocytes $(\mathrm{p}<0.01)$ compared with the control group (Figures $\mathbf{4 a - d}$ and $\mathbf{5}$ ).

The transverse section of cervical spinal cord of the protected group appeared more or less normal. Most of the neurons in both the ventral and dorsal horns appeared almost normal with central nuclei and prominent nucleoli. Some of these neurons had long processes. However, only few degenerated neurons were still detected. Some showed loss of nuclear details while others were shrunken with dark cytoplasm and loss of nuclear details (Figures 6a-c). The neuropil of both the ventral and dorsal horns also appeared more or less normal with few small thin-walled blood vessels. However, small areas of vacuolation were still detected. There was a significant decrease in the number of astrocytes in this group as compared with the NaFtreated group $(\mathrm{p}<0.01)$ (Figures $\mathbf{5}$ and $\mathbf{6 a}$ ). However, there was also a significant difference in the number of astrocytes in this group compared with the control group $(\mathrm{p}<0.01)$ (Figure 5).

In silver-stained sections, the control group showed a number of large argyrophilic multipolar neurons with cen- 

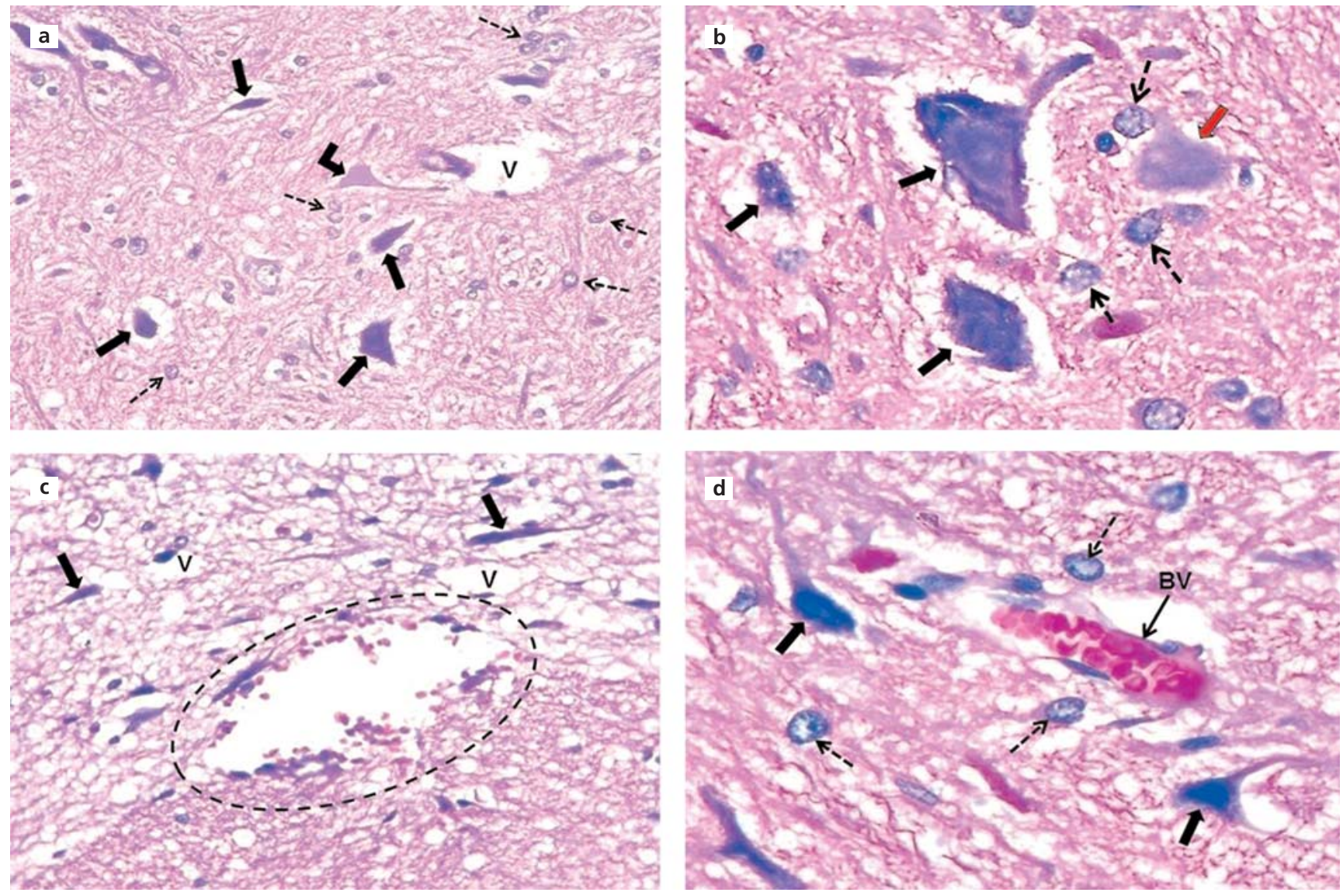

Figure 4. Photomicrographs of transverse sections in the cervical spinal cord of NaF-treated rats. (a) Ventral horn showing many shrunken cells (thick arrows) surrounded by vacuolated neuropil. Another cell shows central chromatolysis (arched arrow). A large area of vacuolation (V) and large number of astrocytes (dashed arrows) are detected in the neuropil (H\&E, $\times 400)$. (b) Higher magnification of the ventral horn showing many shrunken cells (thick arrows) surrounded by vacuolated neuropil. A ghost-like cell (red arrow) and large number of astrocytes (dashed arrows) could be observed $(\mathrm{H} \& \mathrm{E}, \times 1000)$. (c) Dorsal horn showing some shrunken cells (thick arrows). A dilated blood vessel with distorted endothelium (dashed circle) and some areas of vacuolation (V) could be detected in the neuropil (H\&E, $\times 400)$. (d) Higher magnification of the dorsal horn showing some shrunken cells (thick arrows). Large number of astrocytes (dashed arrows) \& a dilated congested blood vessel (BV) could be observed $(H \& E, \times 1000)$. [Color figure can be viewed in the online issue, which is available at www.anatomy.org.tr]

tral nuclei and prominent nucleoli. Some of these neurons had long processes (Figure 7a). The NaF-treated group showed many shrunken cells with dark cytoplasm and loss of nuclear details. The neuropil showed many areas of vacuolation. Also, some degenerated axons with segmental disruption of myeline were observed in the neuropil (Figure 7b). In the protected group, most of the neurons appeared more or less normal with central nuclei and prominent nucleoli. These neurons had long processes. However, few shrunken cells with dark cytoplasm and loss of nuclear details were still detected. These cells had degenerated partially myelinated axons and were surrounded by areas of vacuolation (Figure 7c).

In TB-stained sections, the cytoplasm of motor neurons of the control group was filled with dense Nissl's granules content which appeared dark blue in color
(Figure 8a). In the NaF-treated group, the cytoplasm of motor neurons showed a significant decrease of Nissl's granules content $(\mathrm{p}<0.01)$ that appeared faint blue in color

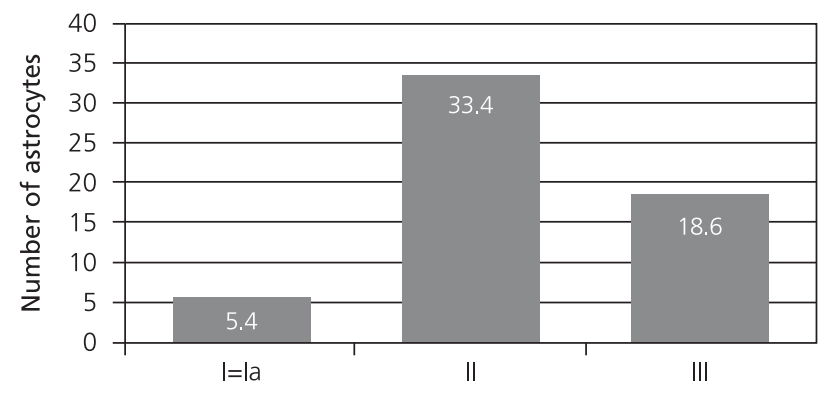

Figure 5. Number of astrocytes in cervical sections of the rat spinal cord. 

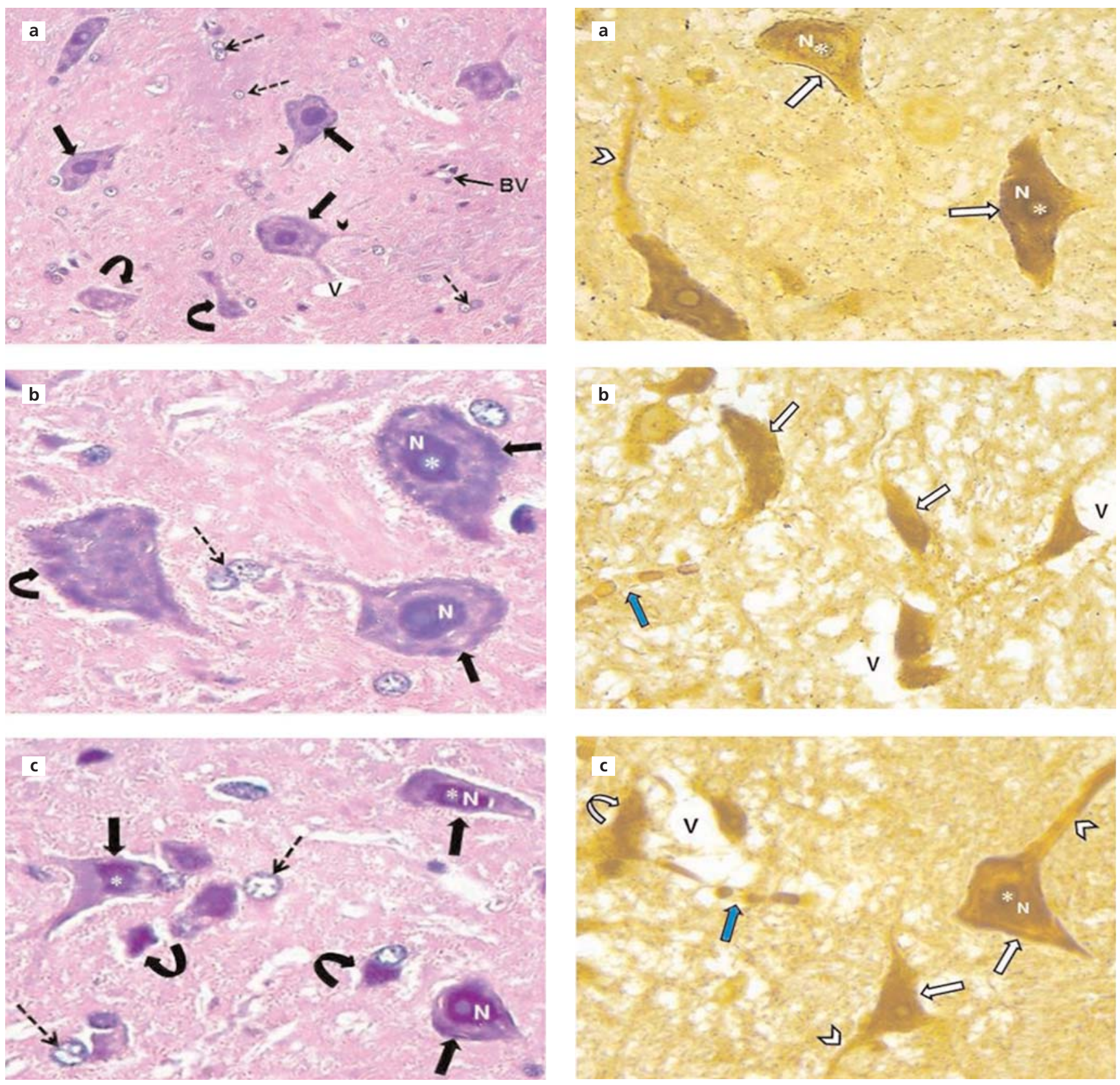

Figure 6. Photomicrographs of transverse sections in the cervical spinal cord of protected rats. (a) Ventral horn showing many more or less normal motor neurons (thick arrows). Some have long processes (arrowheads). However, some shrunken cells with loss of nuclear details (curved arrows) could be observed. A fewer number of astrocytes (dashed arrows), a small thin walled blood vessel (BV) and an area of vacuolation (V) are detected in the neuropil $(H \& E, \times 400)$. (b) Higher magnification of the ventral horn showing some more or less normal motor neurons (thick arrows). Each has a central nucleus ( $\mathrm{N}$ ) with a prominent nucleolus (*). However, another cell shows loss of nuclear details (curved arrow). Average number of astrocytes (dashed arrow) could be detected in the neuropil $\left(H \& E_{1} \times 1000\right)$. (c) Dorsal horn showing many more or less normal sensory interneurons (thick arrows). Each has a central nucleus $(\mathrm{N})$ with a prominent nucleolus $\left({ }^{*}\right)$. However, some shrunken cells (curved arrows) are still observed. Few number of astrocytes (dashed arrows) could be detected in the neuropil (H\&E, $\times 1000)$. [Color figure can be viewed in the online issue, which is available at www.anatomy.org.tr]

Figure 7. Photomicrographs of silver-stained sections in the ventral horn of cervical spinal cord of (a) control group showing number of large argyrophilic multipolar motor neurons (white arrows) with central nuclei $(\mathrm{N})$ and prominent nucleoli (*). Some of these cells have long processes (arrowhead). (b) NaF-treated group showing many shrunken cells with dark cytoplasm and loss of nuclear details (white arrows). Some areas of vacuolation $(\mathrm{V})$ and a degenerated axon with segmental disruption of myeline (blue arrow) could be observed. (c) protected group showing some more or less normal large multipolar motor neurons (white arrows) with central nuclei (N), prominent nucleoli (*) and long processes (arrowheads). However, a shrunken cell (curved arrow) could be observed. This cell has a degenerated axon with segmental disruption of myeline (blue arrow) and is surrounded by vacuolated neuropil (V) (Silver stain, $\times 1000)$. [Color figure can be viewed in the online issue, which is available at www.anatomy.org.tr] 

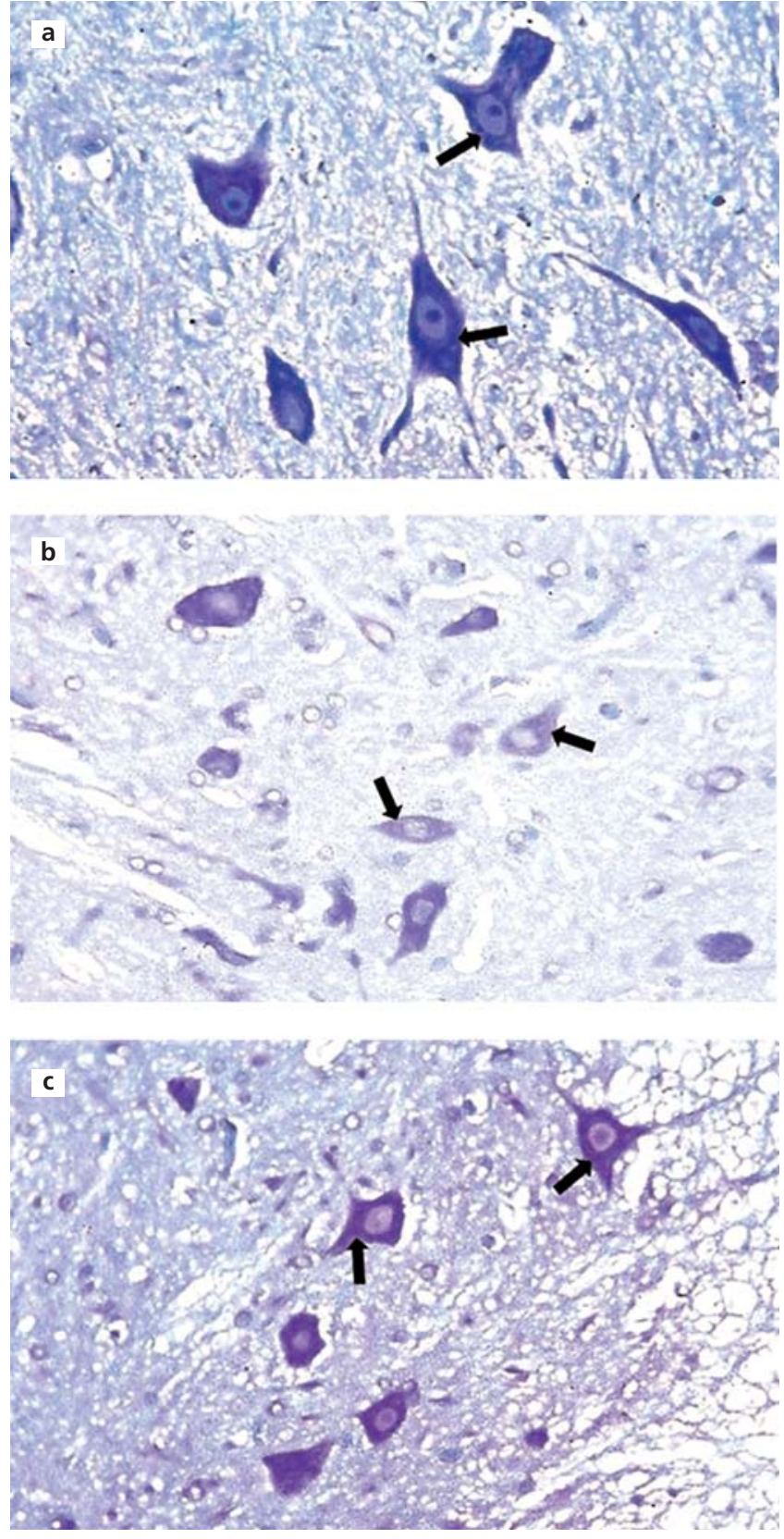

Figure 8. Photomicrographs of TB-stained sections in the ventral horn of cervical spinal cord of (a) control group showing dense Nissl's granules content inside the cytoplasm of the motor neurons which appear dark blue in color (arrows). (b) NaF-treated group showing apparent decrease of Nissl's granules content (arrows) in the motor neurons that appeared faint blue in color. (c) Protected group showing an apparent increase of Nissl's granules content in many of the motor neurons (arrows) which appear dark blue in color as compared to NaF-treated group (Toluidine blue, $\times 400$ ). [Color figure can be viewed in the online issue, which is available at www.anatomy.org.tr]

as compared to the control group (Figures $\mathbf{8 b}$ and $\mathbf{9}$ ). In the protected group, most of the motor neurons showed significant increase of their Nissl's granules content

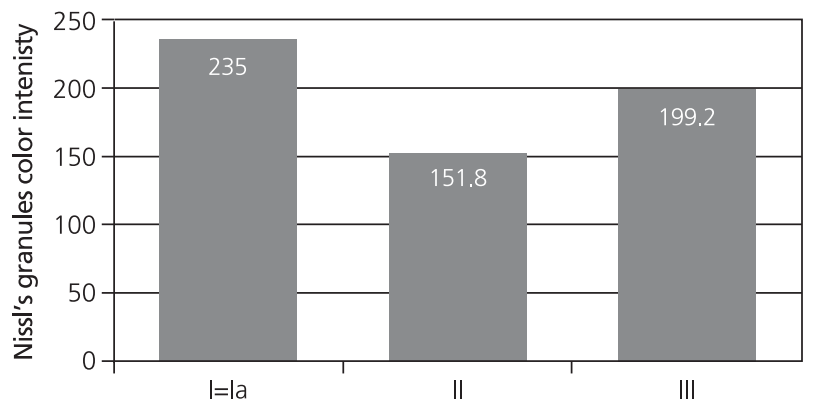

Figure 9. Mean color intensity of Nissl's granules in cervical sections of the spinal cord.

$(\mathrm{p}<0.001)$ and appeared dark blue in color when compared with the NaF-treated group (Figures $\mathbf{8 c}$ and $\mathbf{9}$ ).

In caspase-3-stained sections, the neurons of the control group showed negative immune reaction to caspase3 (Figure 10a). The neurons of the $\mathrm{NaF}$-treated group showed positive immune reaction to caspase- 3 which was indicated by dark brown staining of the cytoplasm and nuclei of these neurons (Figure 10b). In the protected group, some neurons showed negative immune reaction to caspase- 3 while others showed weak positive immune reaction to caspase- 3 which was indicated by light brown staining of the cytoplasm of these neurons (Figure 10c).

In GFAP-stained sections, the control group showed small astrocytes with short processes and faint brown color with GFAP immunostaining (Figure 11a). In the NaFtreated group, the neuropil showed a significant increase in the size of astrocytes $(\mathrm{p}<0.01)$ which had longer processes as compared to the control group (Figures 11b and 12). In the protected group, there was a significant decrease in the number and size of astrocytes $(\mathrm{p}<0.001)$ which had shorter processes as compared to $\mathrm{NaF}$-treated group (Figures 11c and 12).

\section{Electron microscopy findings}

The nerve cells of the control group had regular euchromatic nuclei with fine dispersed chromatin and prominent nucleoli. The cytoplasm contained rough endoplasmic reticulum (RER) and mitochondria. Many free ribosomes in the form of black granules were scattered in the cytoplasm in between the organelles (Figure 13a). The NaFtreated group showed nerve cells with irregular nuclei and condensation of chromatin inside the nucleus. The cytoplasm contained swollen vacuolated mitochondria with destructed cristae. The rough endoplasmic reticulum was dilated taking a globular shape. Also, some areas of vacuolation could be detected inside the cytoplasm (Figures $\mathbf{1 3 b}$ and $\mathbf{c})$. Compared to the $\mathrm{NaF}$-treated group, the 

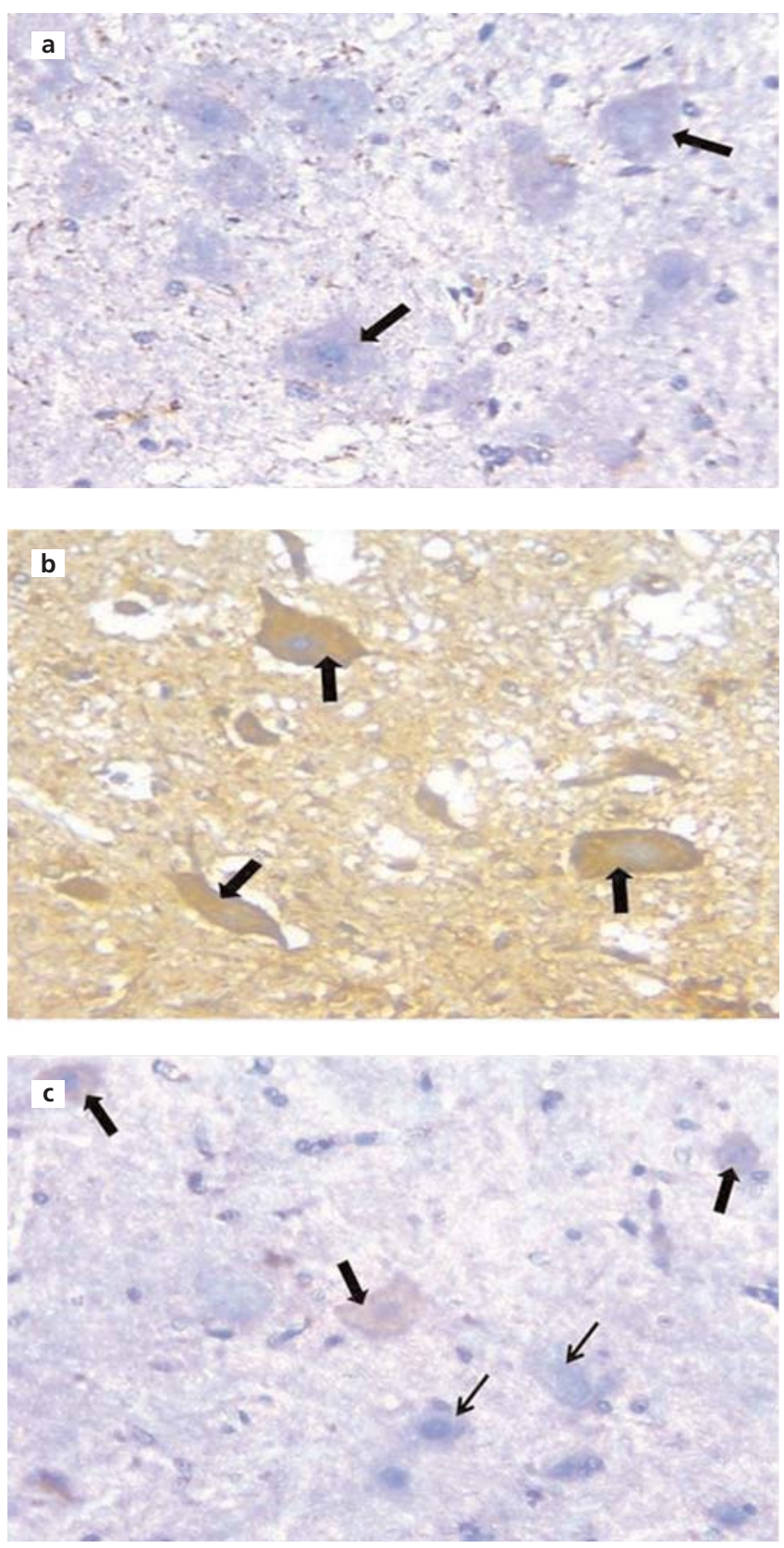

Figure 10. Photomicrographs of caspase-3-immunostained sections in the ventral horn of cervical spinal cord of (a) control group showing negative immune reaction to caspase- 3 which is indicated by the absence of brown staining in the cytoplasm and nuclei of the neurons (arrows). (b) NaF-treated group showing positive immune reaction to caspase-3 which is indicated by dark brown staining of the cytoplasm and nuclei of the neurons (arrows). (c) Protected group showing weak immune reaction to caspase-3 which is indicated by light brown staining of the cytoplasm of some neurons (thick arrows). Other neurons show negative immune reaction to caspase3 (thin arrows) (Immunoreactivity to caspase-3, x400). [Color figure can be viewed in the online issue, which is available at www.anatomy.org.tr]

nerve cells of the protected group were almost normal. The cytoplasm contained more or less normal mitochondria, RER and many free ribosomes. However, small areas
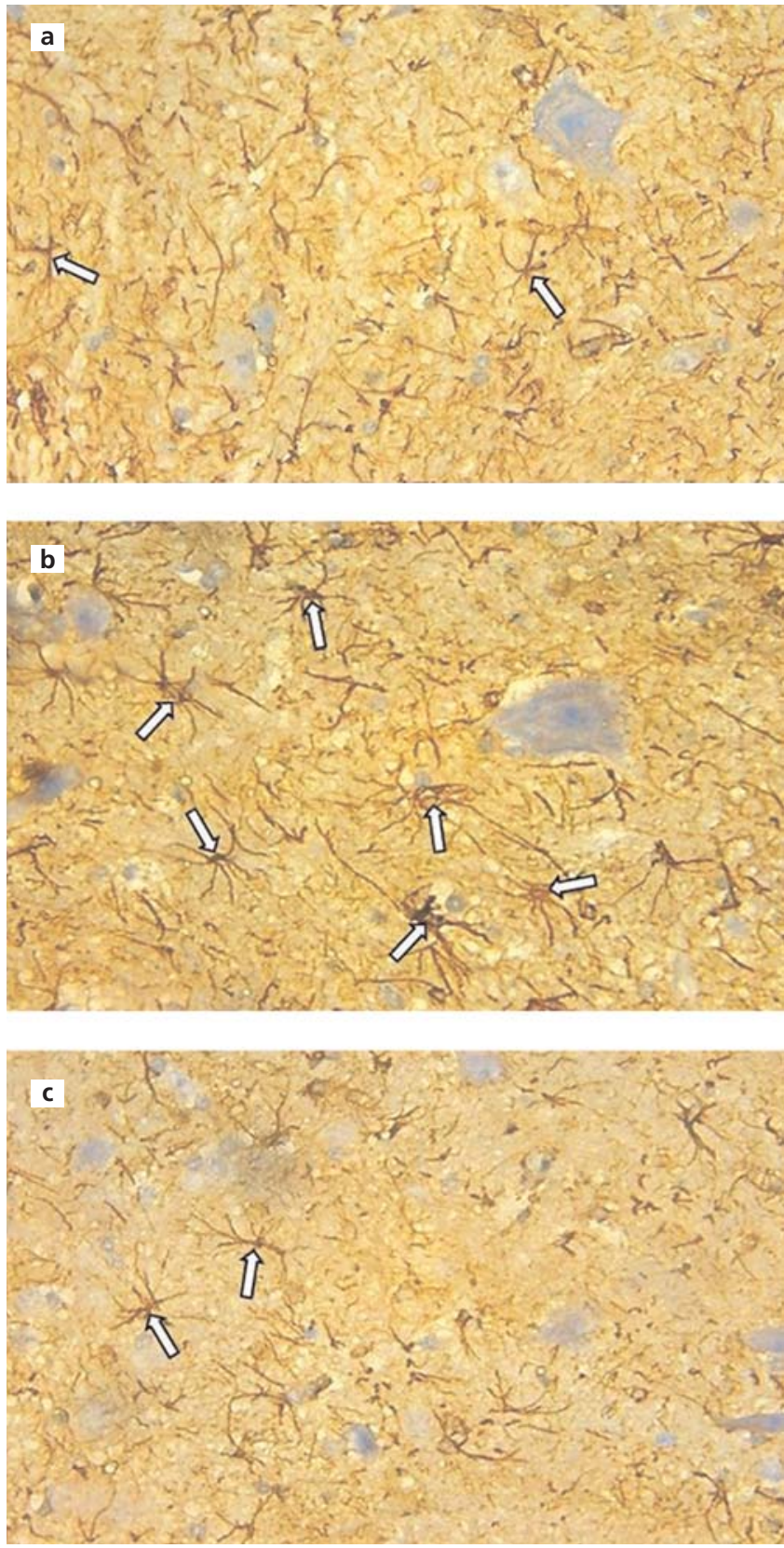

Figure 11. Photomicrographs of GFAP-immunostained sections in the ventral horn of cervical spinal cord of (a) control group showing small astrocytes with short processes and faint brown color (arrows) dispersed among the neurons of the ventral horn. (b) NaF-treated group showing apparent increase in the size of astrocytes (arrows) which have longer processes as compared to control group. (c) Protected group showing average number of astrocytes (arrows) that have shorter processes as compared to NaF-treated group (Immunoreactivity to GFAP $\times 400$ ). [Color figure can be viewed in the online issue, which is available at www.anatomy.org.tr]

of vacuolation could be still detected in the cytoplasm. Except for some condensation of chromatin, the nuclei were apparently normal (Figure 13d). 


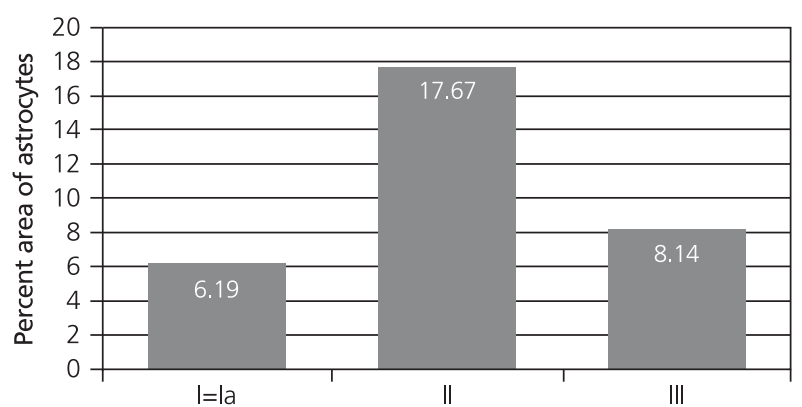

Figure 12. Mean percent area of astrocytes in cervical sections of the spinal cord.

\section{Histological findings for the thoracic spinal cord Light microscopy findings}

In H\&E-stained sections, the transverse section of thoracic spinal cord of the control group was organized into an outer light white matter and inner dark grey matter. The H-shaped grey matter was divided into ventral, lateral and dorsal horns (Figure 14a). The ventral horn showed some large basophilic multipolar motor neurons. The lateral horn showed a number of medium-sized sympathetic neurons, while the dorsal horn showed many small sensory interneurons. Each neuron had a central nucleus with a prominent nucleolus. Some cells had long processes (Figures 14b-f). The neurons were scattered inside eosinophilic neuropil matrix. Inside the neuropil, there were few small thin walled blood vessels and few astrocytes with small vesicular nuclei (Figures 14b-f). The transverse section of thoracic spinal cord of the $\mathrm{NaF}$ treated group showed various degrees of neurodegeneration in the ventral, lateral and dorsal horns. Many cells were shrunken with dark cytoplasm and loss of nuclear details. Other cells appeared as ghost-like cells. Few cells showed central chromatolysis - cytoplasmic hyalinization. The neuropil of the ventral, lateral and dorsal horns showed many areas of haemorrhage and some areas of vacuolation. Moreover, the neuropil showed a significant increase in the number of astrocytes (Figures 15a-f, 16)

Compared to the NaF-treated group, the thoracic spinal cord of the protected group was more or less appearing normal. Most of the neurons in the ventral, lateral and dorsal horns appeared more or less normal with central nuclei and prominent nucleoli. Some of these neurons had long processes. However, only few degenerated neurons were still detected. Some showed loss of nuclear details, others were shrunken with dark cytoplasm and loss of nuclear details, while there were some cells which appeared ghost-like (Figures 17a-d). The neuropil of the ventral, lateral and dorsal horns was more or less normal.
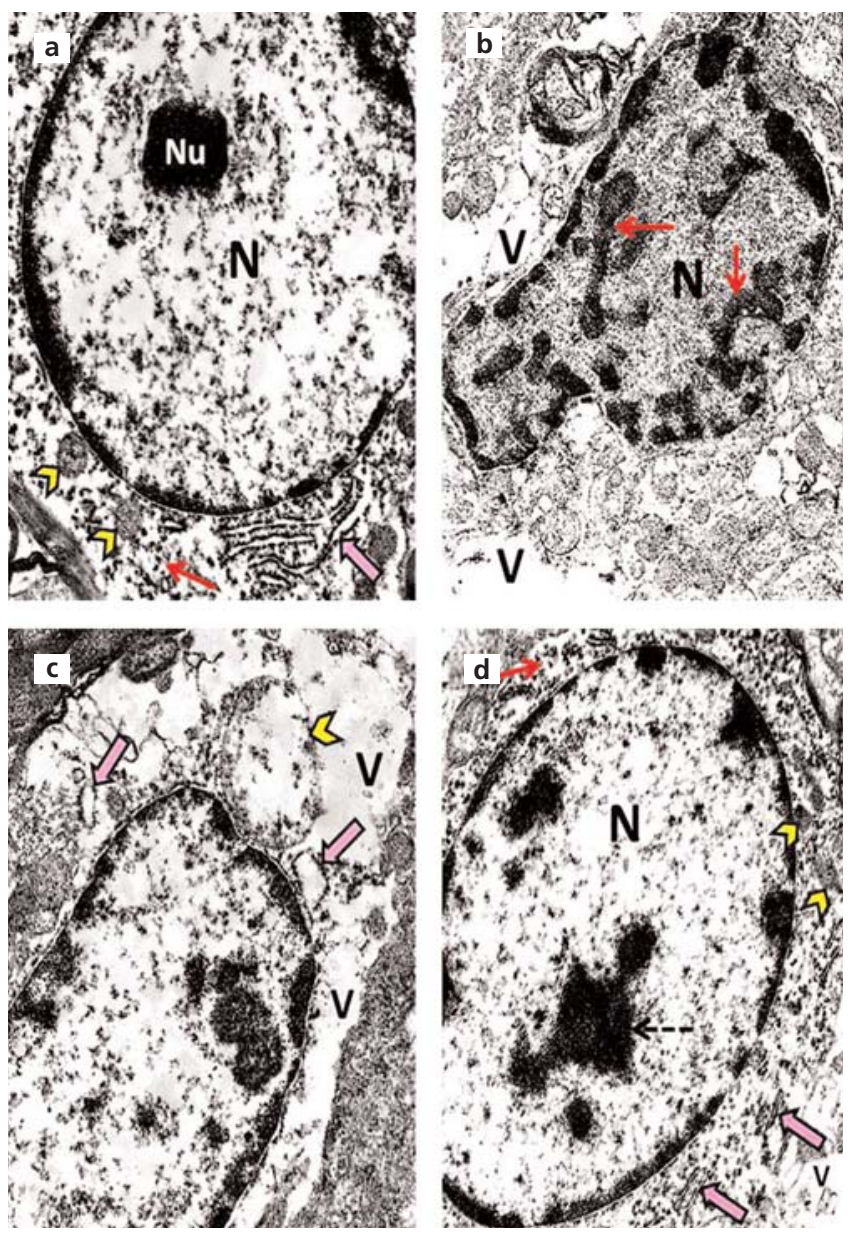

Figure 13. Transmission electron micrographs of transverse sections in the cervical spinal cord of (a) control group showing a nerve cell containing regular euchromatic nucleus $(\mathrm{N})$ with fine dispersed chromatin and prominent nucleolus (Nu). The cytoplasm contains RER (pink arrow) and mitochondria (yellow arrowheads). Many free ribosomes (red arrow) lie between the organelles. (b, c) NaF-treated group showing markedly irregular nucleus $(\mathrm{N})$ with marked condensation of chromatin (red arrows). The cytoplasm contains dilated RER (pink arrows) and markedly swollen mitochondria with destructed cristae (yellow arrowhead). Large areas of vacuolation (V) could be also detected in the cytoplasm. (d) Protected group showing an apparently normal nerve cell with regular nucleus $(\mathrm{N})$. However, the nucleus still shows some condensation of chromatin (dashed arrow). The cytoplasm contains more or less normal RER (pink arrows), mitochondria (yellow arrowheads) and many free ribosomes (red arrow). However, small area of vacuolation $(V)$ could be still detected in the cytoplasm $(\times 4000)$. [Color figure can be viewed in the online issue, which is available at www.anatomy.org.tr]

However, some areas of vacuolation were still detected in the neuropil. There was a significant decrease in the number of astrocytes in this group as compared with the NaFtreated group (Figures 16, 17a-d).

In siver-stained sections, the control group showed a number of large argyrophilic multipolar neurons with 

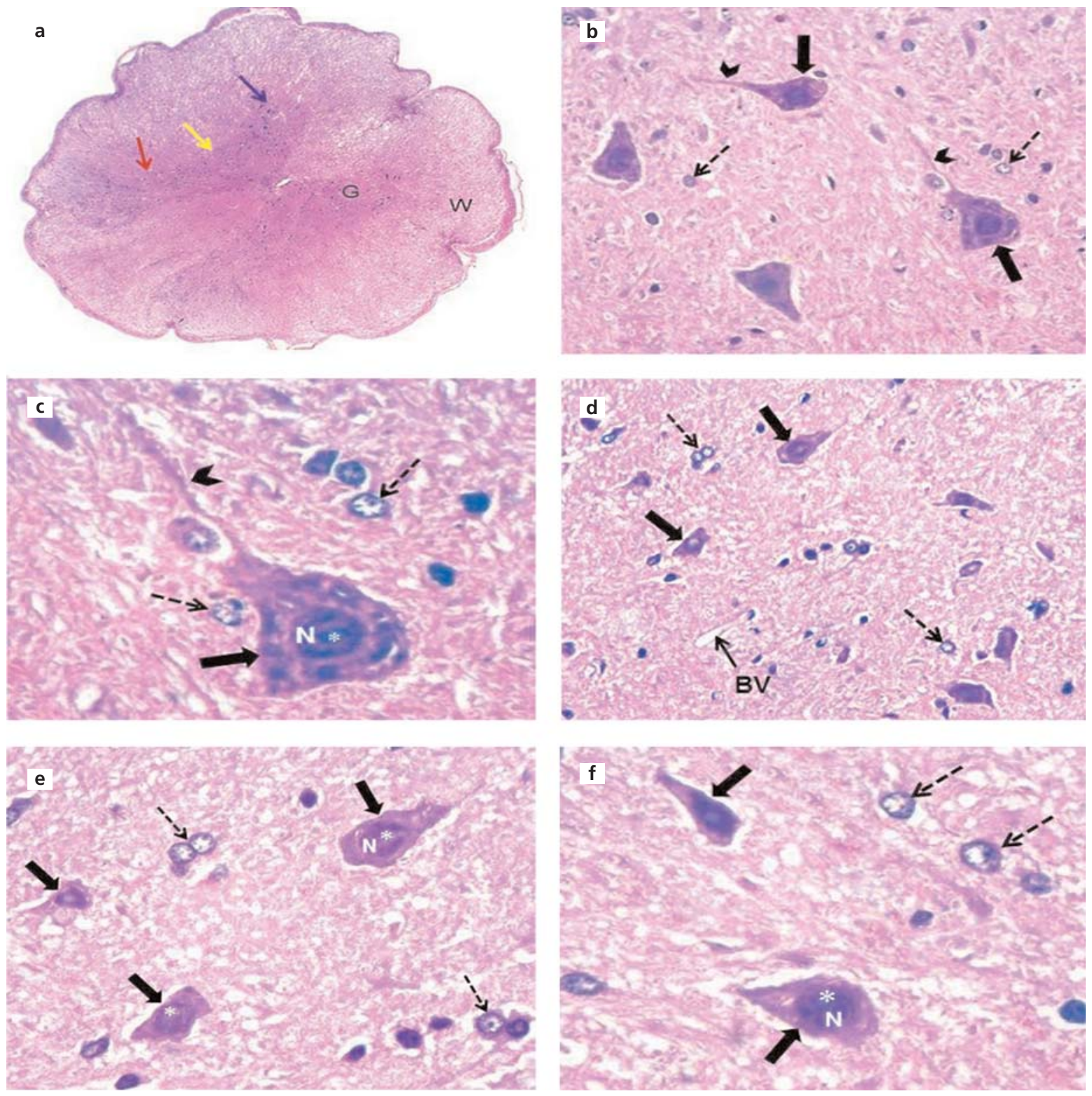

Figure 14. Photomicrographs of transverse sections in the thoracic spinal cord of control rats (a) showing outer white matter (W) and inner grey matter $(\mathrm{G})$ which is divided into dorsal horn (red arrow), lateral horn (yellow arrow) and ventral horn (blue arrow) (H\&E, $\times 40$ ). (b) Ventral horn showing number of large multipolar motor neurons (thick arrows) with long processes (arrowheads) and few astrocytes (dashed arrows) $(H \& E, \times 400)$. (c) Higher magnification of the ventral horn showing a large multipolar motor neuron (thick arrow) having a central nucleus $(\mathrm{N})$ with a prominent nucleolus $(*)$. The cell has long process (arrowhead). Few astrocytes (dashed arrows) are observed in the neuropil (H\&E, $\times 1000)$. (d) Lateral horn showing number of medium sized sympathetic neurons (thick arrows). Few astrocytes (dashed arrows) and a small thin walled blood vessel (BV) are observed in the neuropil (H\&E, x400). (e) Higher magnification of the lateral horn showing some medium sized sympathetic neurons (thick arrows). Each has a central nucleus (N) with a prominent nucleolus (*). Few astrocytes (dashed arrows) are scattered in the neuropil (H\&E, $\times 1000)$. (f) Higher magnification of the dorsal horn showing number of small sensory interneurons (thick arrows). Each has a central nucleus (N) with a prominent nucleolus $\left.{ }^{*}\right)$. Few astrocytes (dashed arrows) are observed in the neuropil $(H \& E, \times 1000)$. [Color figure can be viewed in the online issue, which is available at www.anatomy.org.tr]

central nuclei and prominent nucleoli. Some of these neurons had long processes. The neuropil showed some nodded myelinated axons (Figure 18a). The NaF-treated group showed many shrunken cells with dark cytoplasm and loss of nuclear details. The neuropil showed some areas of vacuolation and some degenerated axons with segmental disruption of myeline (Figure 18b). In silverstained sections of the protected group, most of the neu- 

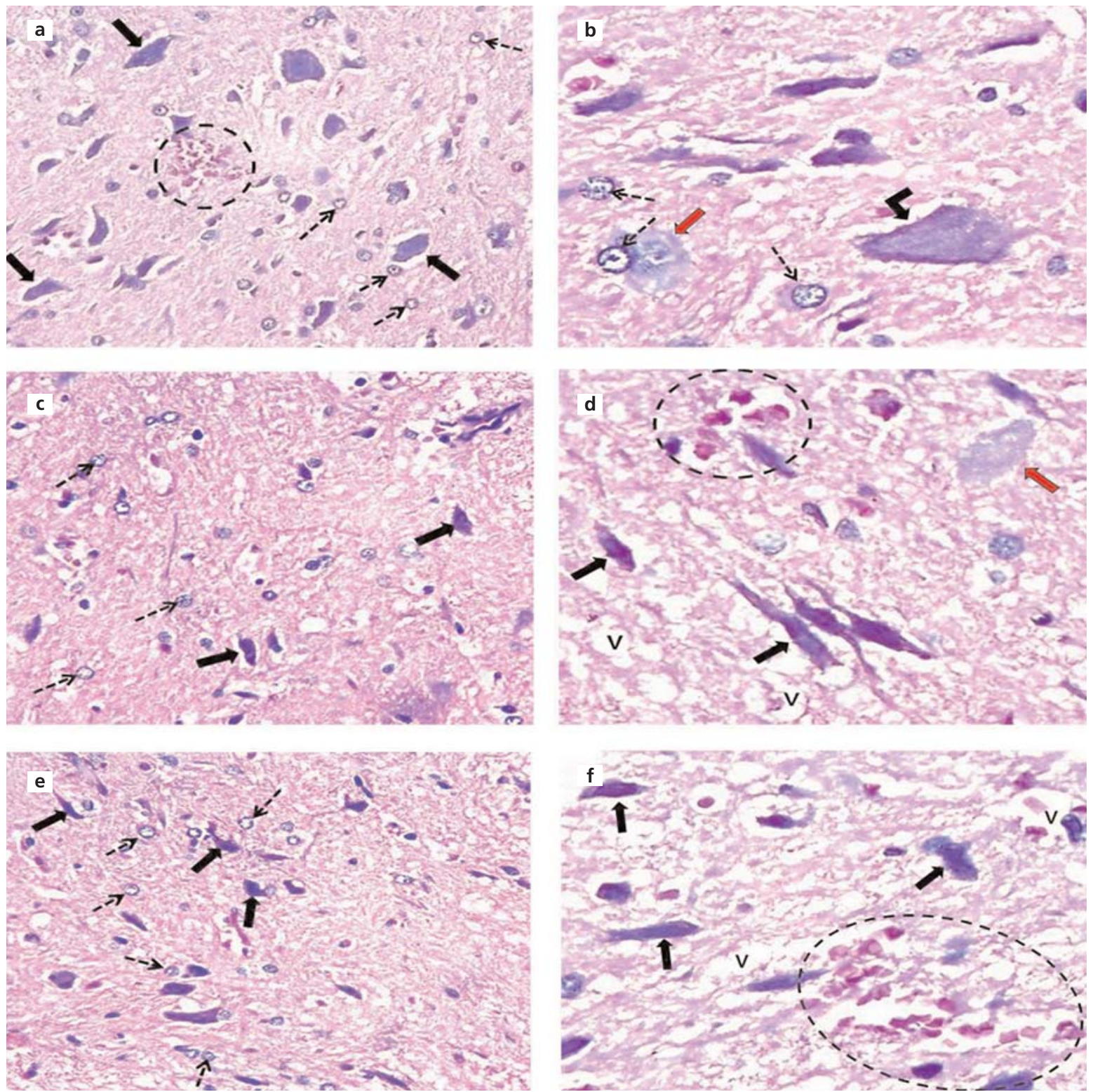

Figure 15. Photomicrographs of transverse sections in the thoracic spinal cord of NaF-treated rats. (a) Ventral horn showing many shrunken cells (thick arrows), large number of astrocytes (dashed arrows) and an area of hemorrhage (dashed circle) (H\&E, $\times 400)$. (b) Higher magnification of the\&ventral horn showing a cell with central chromatolysis (arched arrow) and another ghost-like cell (red arrow). Large number of astrocytes (dashed arrows) is detected in the neuropil (H\&E, $\times 1000)$. (c) Lateral horn showing some shrunken cells (thick arrows) and large number of astrocytes (dashed arrows) (H\&E, $\times 400)$. (d) Higher magnification of the lateral horn showing many shrunken cells (black arrows) and a ghost-like cell (red arrow). An area of hemorrhage (dashed circle) and some areas of vacuolation (V) could be detected in the neuropil (H\&E, $\times 1000)$. (e) Dorsal horn showing many shrunken cells (thick arrows) and a large number of astrocytes (dashed arrows) (H\&E, x400). (f) Higher magnification of the dorsal horn showing many shrunken cells (thick arrows). A large area of hemorrhage (dashed circle) and many areas of vacuolation (V) could be detected in the neuropil (H\&E, $\times 1000$ ). [Color figure can be viewed in the online issue, which is available at www.anatomy.org.tr]

rons appeared more or less normal with central nuclei and prominent nucleoli. Some of these neurons had long processes and others had normal nodded myelinated axons. However, few shrunken cells with dark cytoplasm and loss of nuclear details were still observed. The neu- ropil was more or less normal except for small areas of vacuolation (Figure 18c).

In TB-stained sections, the cytoplasm of motor neurons of the control group was filled with dense Nissl's granules content which appeared dark blue in color 


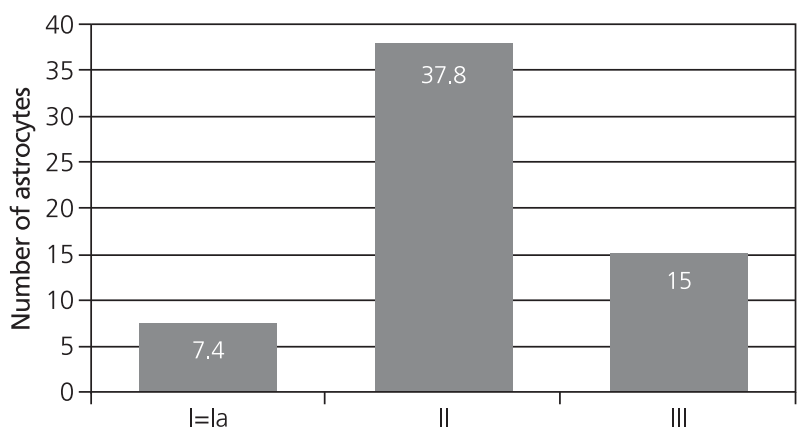

Figure 16. The number of astrocytes in thoracic sections of the rat spinal cord.
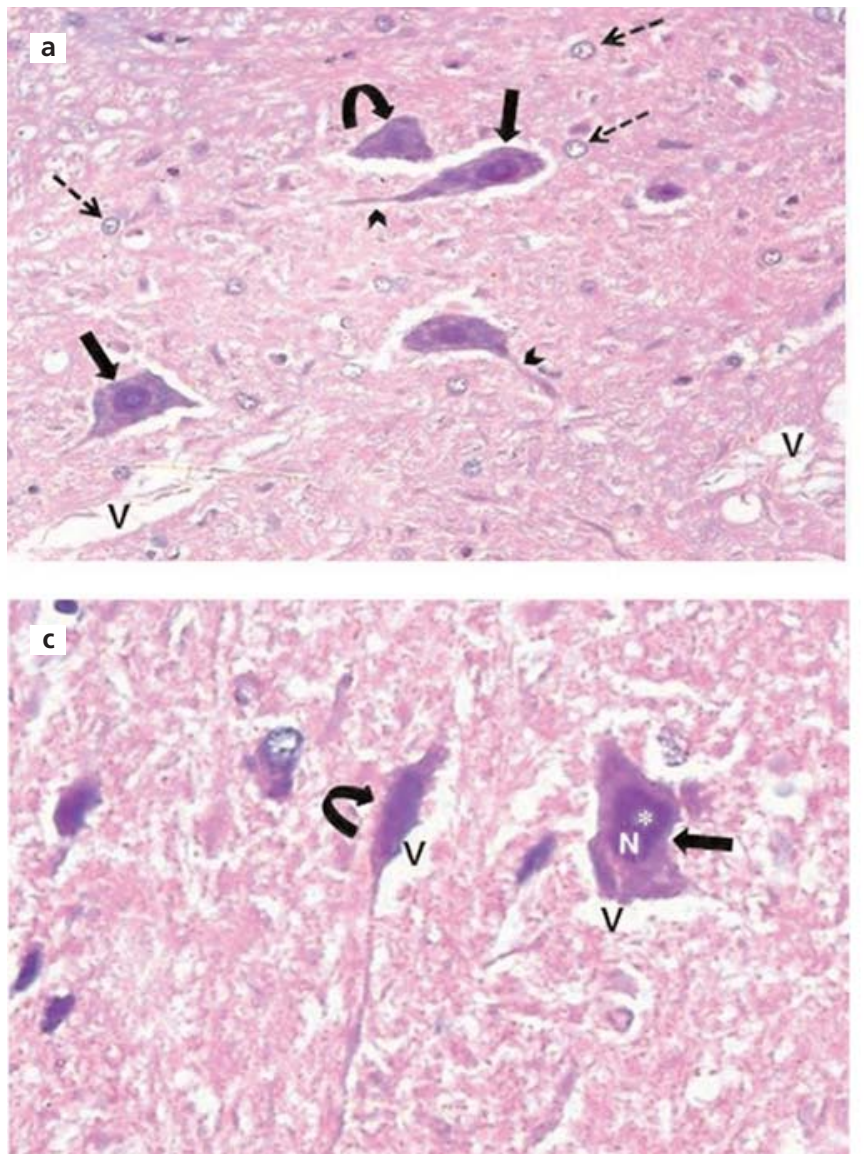

(Figure 19a). In the NaF-treated group, the cytoplasm of motor neurons showed a significant decrease of Nissl granules content that appeared faint blue in color as compared to the control group (Figure 19b). In the protected group, most of the motor neurons showed a significant increase in Nissl's granules content and appeared dark blue in color when compared with the $\mathrm{NaF}$-treated group (Figure 19c).

In caspase-3-stained sections, the neurons of the control group showed negative immune reaction to caspase- 3 (Figure 20a). The neurons of the $\mathrm{NaF}$-treated group showed positive immune reaction to caspase- 3 which was indicated by dark brown staining of the cytoplasm and
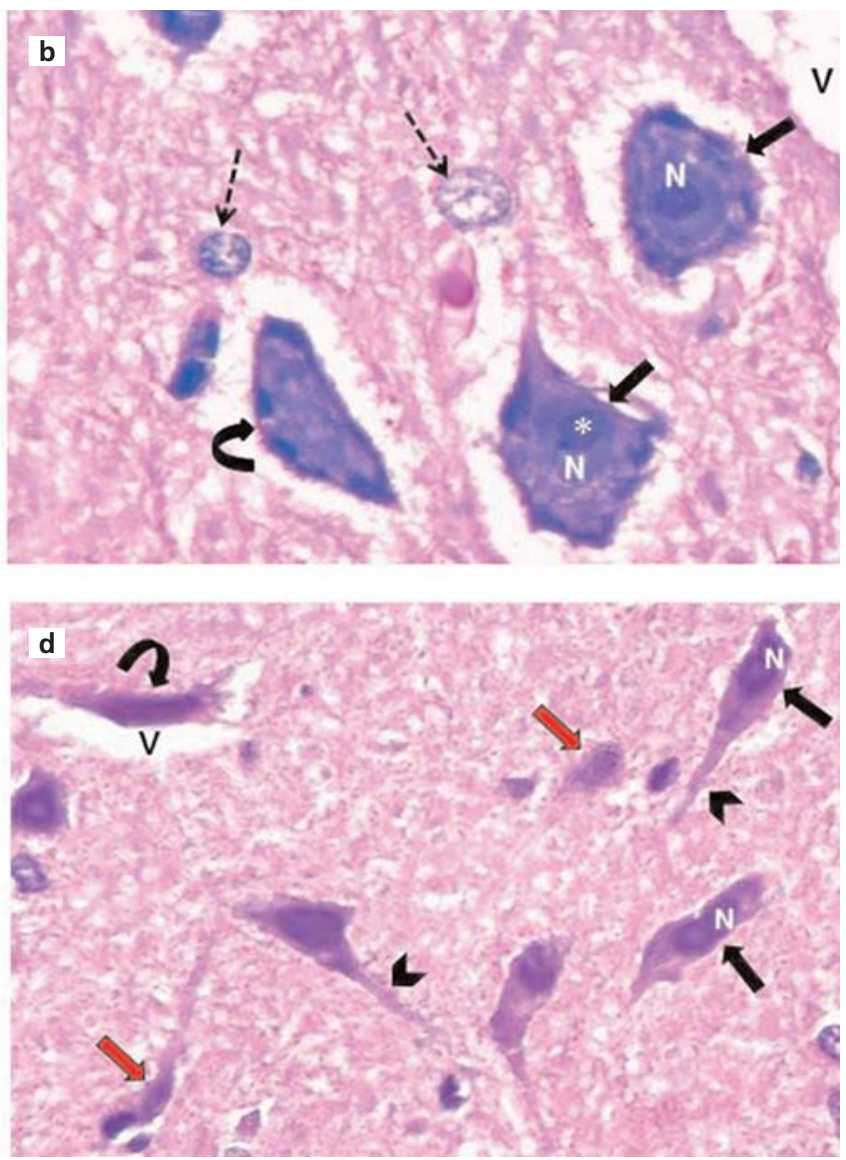

Figure 17. Photomicrographs of transverse sections in the thoracic spinal cord of protected rats. (a) Ventral horn showing many more or less normal motor neurons (thick arrows). Some of them have long processes (arrowheads). However, another cell shows loss of nuclear details (curved arrow). Average number of astrocytes (dashed arrows) and some areas of vacuolation (V) are detected in the neuropil (H\&E, $\times 400)$. (b) Higher magnification of the ventral horn showing some more or less normal motor neurons (thick arrows). Each has a central nucleus (N) with a prominent nucleolus (*). However, another cell shows loss of nuclear details (curved arrow). Average number of astrocytes (dashed arrows) and an area of vacuolation (V) could be detected in the neuropil (H\&E, $\times 1000)$. (c) Higher magnification of the lateral horn showing a more or less normal sympathetic neuron (thick arrow) with central nucleus $(\mathrm{N})$ and a prominent nucleolus $\left(^{*}\right)$. Another shrunken cell (curved arrow) could be observed. Both cells are surrounded by slightly vacuolated neuropil (V) (H\&E, $\times 1000)$. (d) Higher magnification of the dorsal horn showing many more or less normal cells (black arrows) with central nuclei $(\mathrm{N})$ and prominent nucleoli $(*)$. Some have long processes (arrowheads). Another cell is shrunken (curved arrow) and surrounded by vacuolated neuropil (V). Some ghost-like cells (red arrows) could be also observed $(H \& E, \times 1000)$. [Color figure can be viewed in the online issue, which is available at www.anatomy.org.tr] 

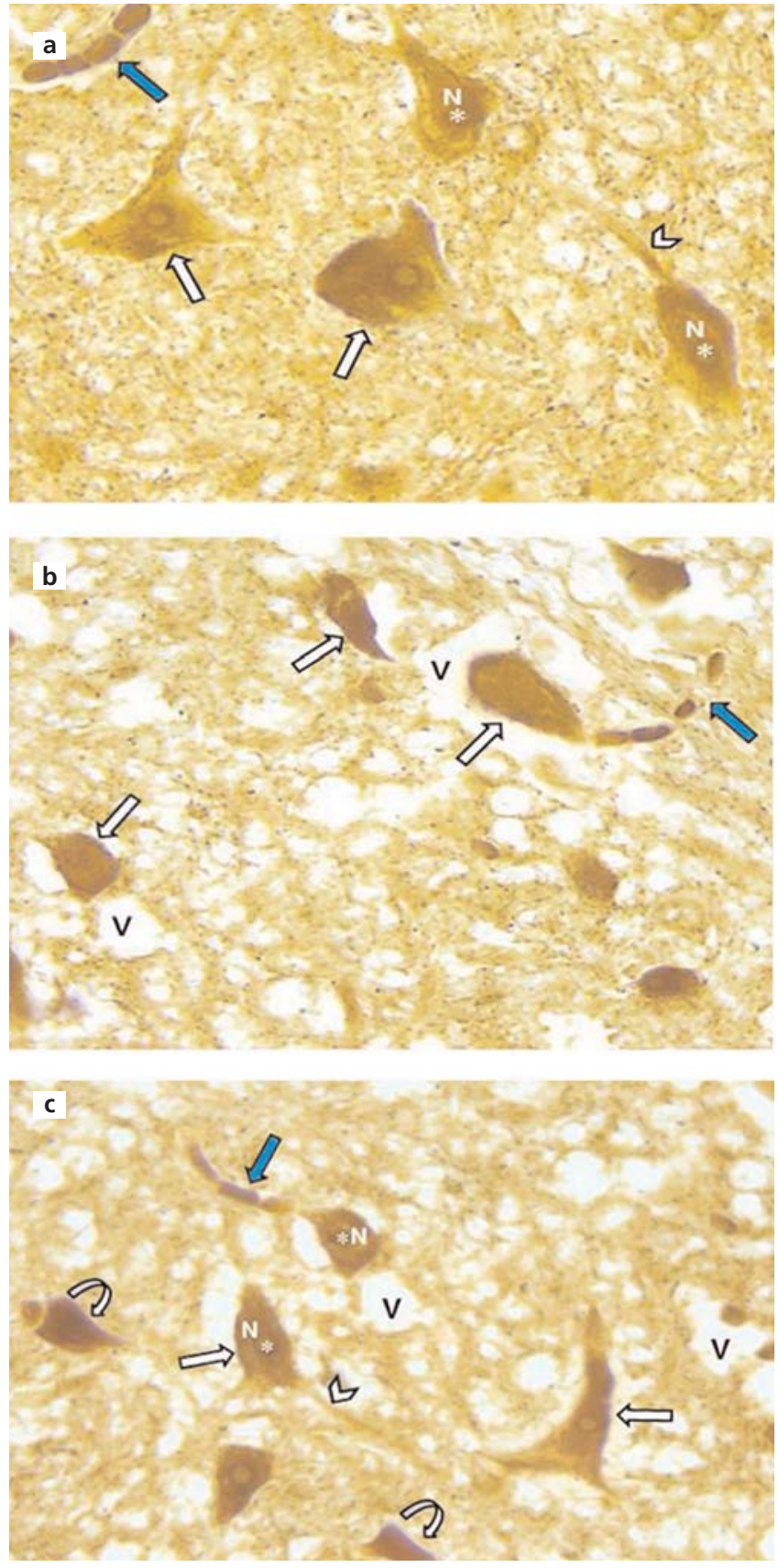

Figure 18. Photomicrographs of silver-stained sections in the ventral horn of the thoracic spinal cord of (a) control group showing number of large argyrophilic multipolar neurons (white arrows) with central nuclei $(\mathrm{N})$ and prominent nucleoli (*). Some have long processes (arrowhead). A large nodded myelinated axon could be detected (blue arrow). (b) NaF-treated group showing many shrunken cells with dark cytoplasm and loss of nuclear details (white arrows). A degenerated axon with segmental disruption of myeline (blue arrow) and some areas of vacuolation (V) could be detected in the neuropil. (c) Protected group showing many more or less normal neurons (white arrows) with central nuclei $(\mathrm{N})$ and prominent nucleoli (*). One of these neurons has long process (arrowhead) while another neuron has a normal nodded myelinated axon (blue arrow). However, few shrunken cells (curved arrows) could be observed. Small areas of vacuolation (V) could be still detected in the neuropil (Silver stain, $\times 1000$ ). [Color figure can be viewed in the online issue, which is available at www.anatomy.org.tr]
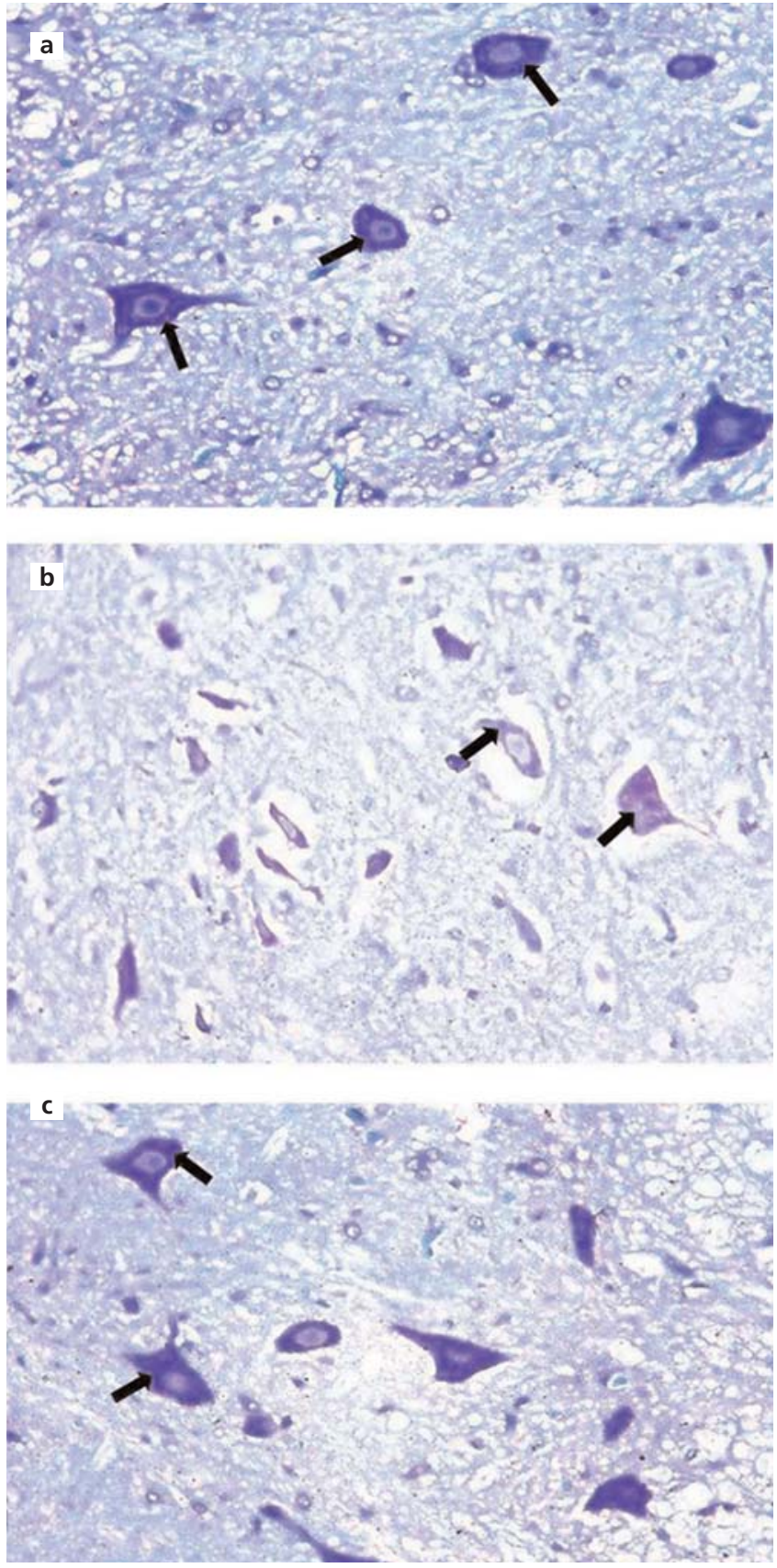

Figure 19. Photomicrographs of TB-stained sections in the ventral horn of thoracic spinal cord of (a) control group showing the dense Nissl's granules content inside the cytoplasm of the motor neurons which appear dark blue in color (arrows). (b) NaF-treated group showing an apparent decrease of Nissl's granules content (arrows) in some of the motor neurons that appear faint blue in color as compared to control group. (c) Protected group showing an increase of Nissl's granules content in many of the motor neurons (arrows) which appear dark blue in color as compared to NaF-treated group (Toluidine blue, $\times 400$ ). [Color figure can be viewed in the online issue, which is available at www.anatomy.org.tr] 
nuclei of these neurons (Figure 20b). In the protected group, the neurons showed weak immune reaction to caspase- 3 which was indicated by light brown staining of the cytoplasm of these neurons (Figure 20c).

In GFAP-stained sections, the control group showed few small astrocytes with short processes and faint brown color with GFAP immunostaining (Figure 21a). The $\mathrm{NaF}$-treated group showed a significant increase in the number and size of astrocytes which had longer processes as compared to the control group (Figure 21b). In the protected group, there was a significant decrease in the number and size of astrocytes which had shorter processes as compared to the NaF-treated group (Figure 21c)

\section{Electron microscopy findings}

The nerve cells of the control group had regular euchromatic nuclei with fine dispersed chromatin and prominent nucleoli. The cytoplasm contained RER, Golgi apparatus and mitochondria. Many free ribosomes in the form of black granules were scattered in the cytoplasm in between the organelles (Figure 22a).

The NaF-treated group showed nerve cells with abnormal nuclei. One section showed markedly irregular nucleus with condensation of chromatin and surrounded by some lysosomes. Another section showed marked indentation of the nucleus. The cytoplasm contained some swollen vacuolated mitochondria and dilated RER. Also, some areas of vacuolation could be detected inside the cytoplasm (Figures $\mathbf{2 2} \mathbf{b}$ and $\mathbf{c}$ )

Compared to the NaF-treated group, the thoracic spinal cord of the protected group was almost normal. The cytoplasm of the nerve cells contained more or less normal RER, mitochondria and many free ribosomes. However, small areas of vacuolation could be still detected in the cytoplasm. Except for some condensation of chromatin, the nuclei were apparently normal (Figure 22d).

\section{Agarose gel electrophoresis findings}

In both the cervical and thoracic segments of the spinal cord, the negative control and the positive control subgroups showed no apoptotic bands. In the $\mathrm{NaF}$-treated group, apoptotic bands in the form of a ladder-like DNA fragmentation pattern (a characteristic of apoptosis) were detected. In the protected group, the apoptotic bands could be detected, but lesser than the NaF-treated group (Figures 23a and $\mathbf{b}$ ).

\section{Discussion}

Fluoride is a two-edged sword for human health. Fluoridation of drinking water seems to be effective for its clarification and treatment of dental caries, whereas undesirable adverse effects of fluoride have been reported. Fluoride is completely and quickly absorbed from the gastrointestinal tract and affects many organs. ${ }^{[20]}$ Few studies related to the effect of oral ingestion of $\mathrm{NaF}$ on the spinal cord have been reported. So, the current study was designed to evaluate the effect of oral intake of $\mathrm{NaF}$, which is one of the major routes of fluoride, on the structure of the spinal cord with or without green tea.

The spinal cord was chosen for this study as most of the previous studies focused on the effects of fluorides on calcified and hard tissues of the body such as bone and teeth. However, during the past decade researchers all over the world have felt that there is a need to study the effects of fluorides on other tissues of the body including central nervous system, as the fluorides are known to cross blood brain barrier. ${ }^{[21]}$

In the present study, the animals of negative control subgroup showed a significant increase in the body weight at the end of the experiment. This was in agreement with Soliman et al ${ }^{[18]}$ who reported that balanced diet feeding resulted in a significant increase in the body weight of rats. The animals of fluoride treated group in this study showed a significant decrease in the body weight at the end of the experiment. This finding was in agreement with Reddy et al. ${ }^{[22]}$ who reported a significant reduction in body weights of the NaF-treated animals relative to the control group. Trivedi et al. ${ }^{[23]}$ attributed this reduction in body weight after $\mathrm{NaF}$ treatment to the lower food consumption resulting in decreased protein synthesis and lower energy metabolism. Whereas, NourEdien et al ${ }^{[24]}$ stated that reduction in the body weight could be explained by the direct corrosive effect of fluoride on gastric mucosa and gut. In addition, Warren and Mitchell ${ }^{[25]}$ referred the decrease in body weight to the inhibitory effect of fluoride on protein metabolism and enzyme activity. In this study, the animals of green tea treated subgroup showed a significant decrease in the body weight at the end of the experiment. Also, addition of green tea to the $\mathrm{NaF}$ resulted in a significant decrease in the body weight of rats. This finding was in agreement with $\mathrm{Lu}$ et al. ${ }^{[2]}$ who stated that supplementation of green tea polyphenols in the drinking water reduced the body weight of rats. Farooqui ${ }^{[27]}$ tried to explain the role of green tea in promoting weight loss. He stated that epigallocatechin-3-gallate (EGCG) present in green tea reduces food uptake, lipid absorption and gluconeogenesis. He added that EGCG also inhibits adipocyte mitogenesis and stimulates fat cell apoptosis. Cooper et al. ${ }^{[28]}$ attributed the antiobesity effects of green tea to the increase in thermogenesis (increased caloric expenditure). They stated that a probable theory for the thermogenic effect of green tea is an increase in level of nor- 

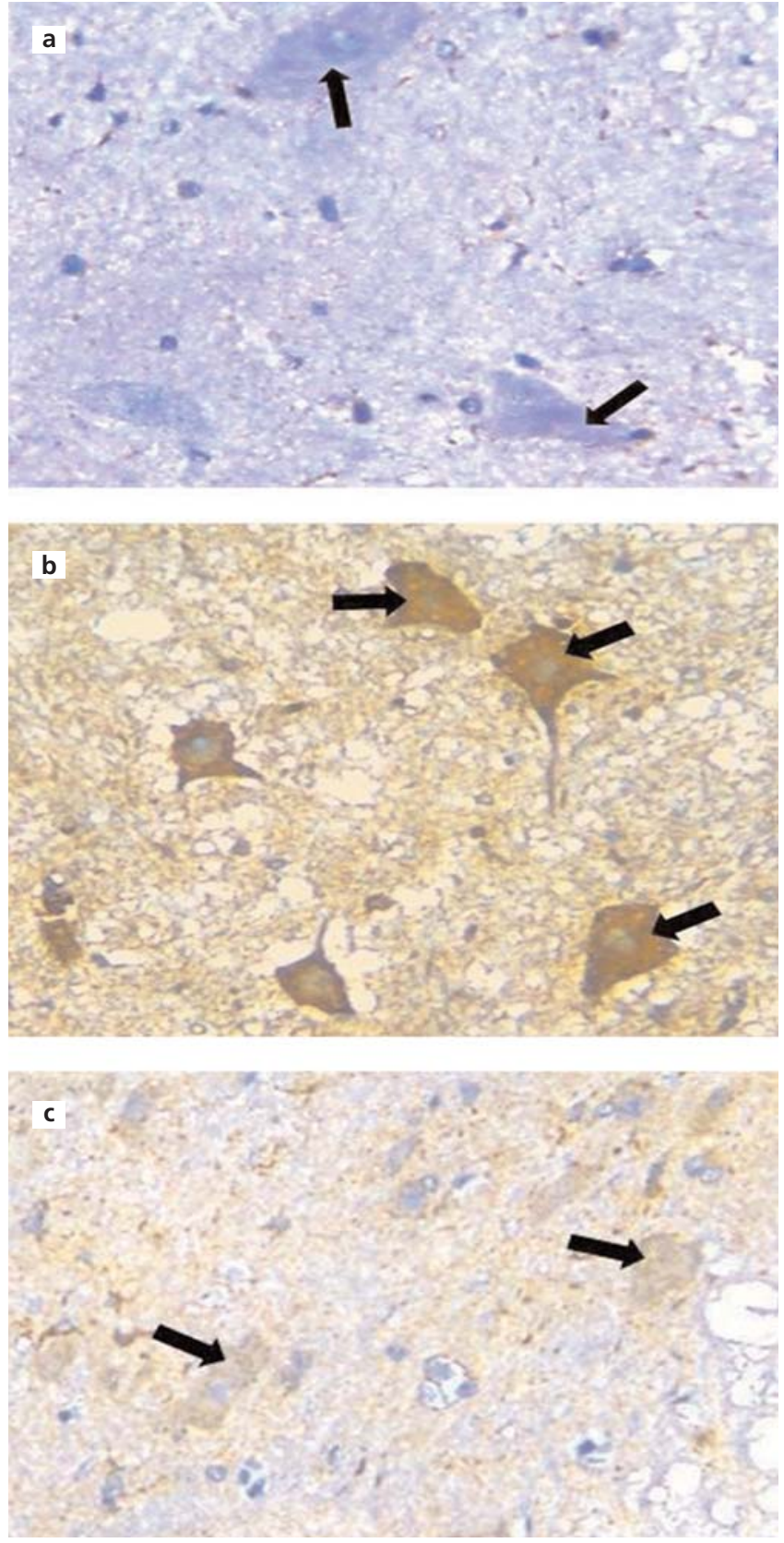

Figure 20. Photomicrographs of caspase-3-immunostained sections in the ventral horn of thoracic spinal cord of (a) control group showing negative immune reaction to caspase- 3 which is indicated by absence of brown staining in the cytoplasm and nuclei of the neurons (arrows). (b) NaFtreated group showing positive immune reaction to caspase- 3 which is indicated by dark brown staining of the cytoplasm and nuclei of the neurons (arrows). (c) Protected group showing weak immune reaction to caspase-3 which is indicated by light brown staining of the cytoplasm of the neurons (arrows) (Immunoreactivity to caspase-3, ×400). [Color figure can be viewed in the online issue, which is available at www.anatomy.org.tr]

epinephrine, because catechin polyphenols are known to inhibit catechol-O-methyltransferase; the enzyme that degrades norepinephrine.
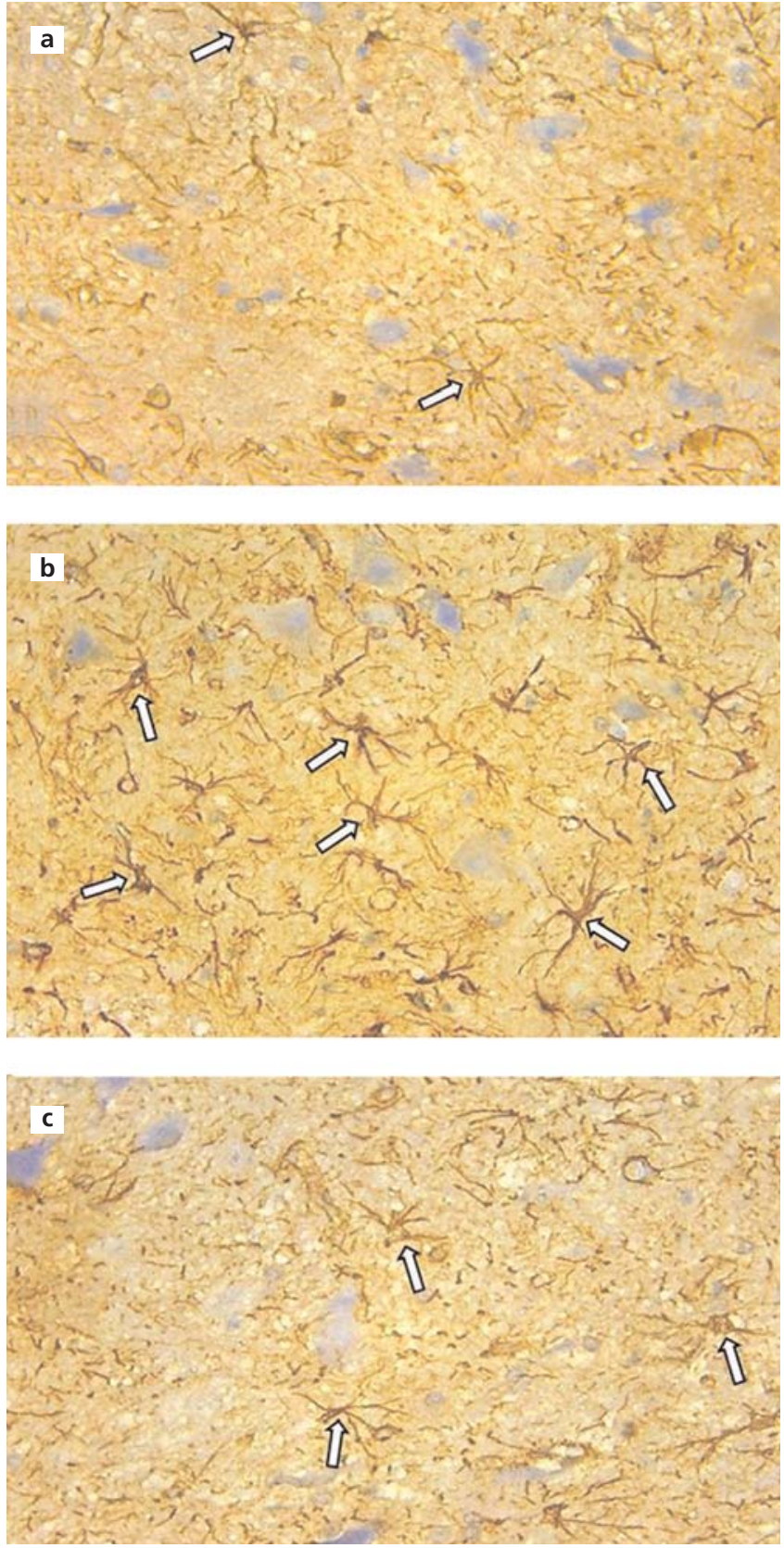

Figure 21. Photomicrographs of GFAP-immunostained sections in the ventral horn of thoracic spinal cord of (a) control group showing few small astrocytes with short processes and faint brown color (arrows) dispersed among the neurons of the ventral horn. (b) NaF-treated group showing an apparent increase in the number and size of astrocytes (arrows). These astrocytes show longer processes as compared to control group. (c) Protected group showing an average number of astrocytes (arrows) that have shorter processes as compared to NaF-treated group (Immunoreactivity to GFAP $\times 400$ ). [Color figure can be viewed in the online issue, which is available at www.anatomy.org.tr]

In the present study, histological results of NaF-treated rats showed various degrees of neural degeneration. Many cells were shrunken with dark cytoplasm and loss of 

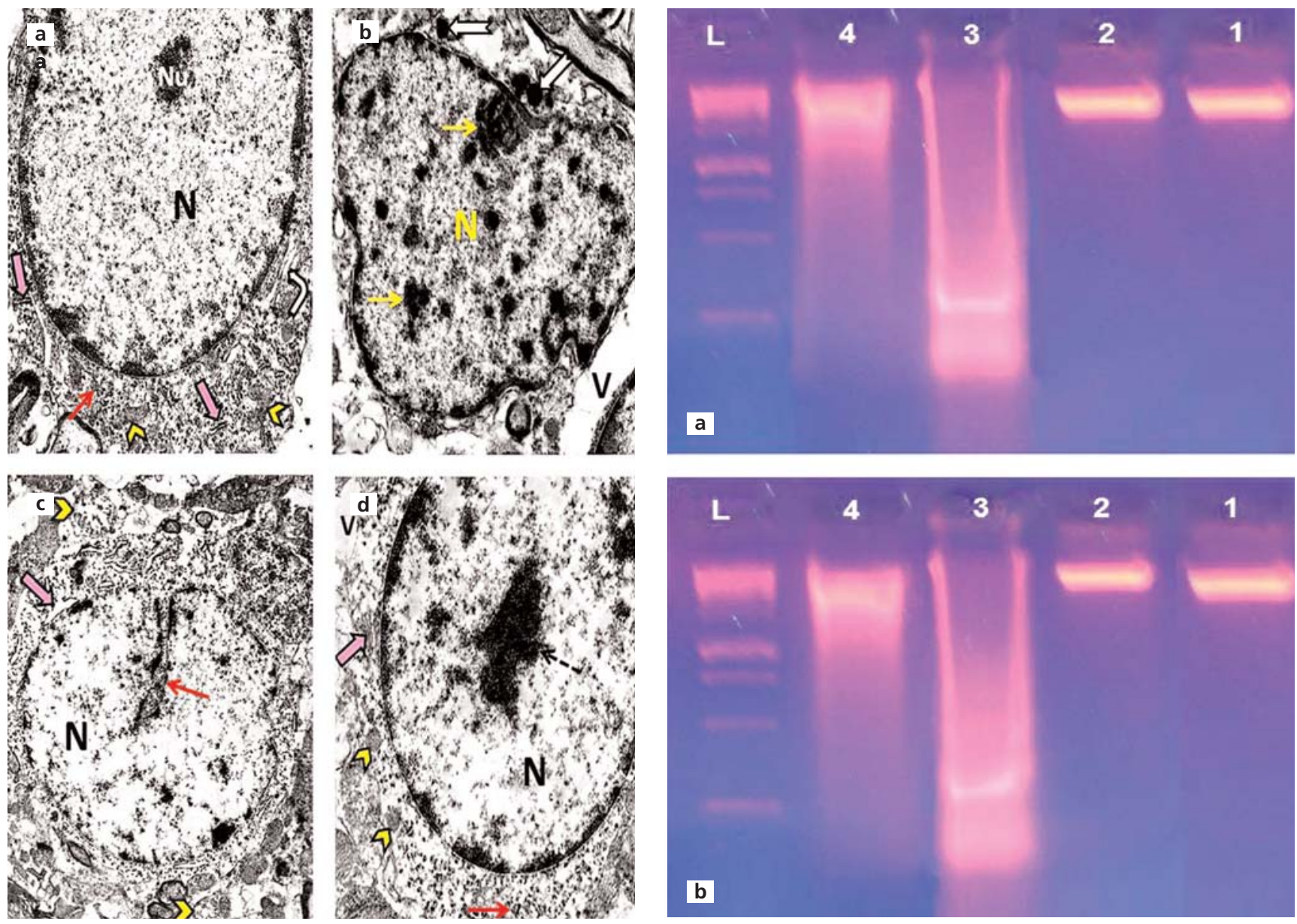

Figure 22. Transmission electron micrographs of transverse sections in the thoracic spinal cord of (a) control group showing a nerve cell containing regular euchromatic nucleus $(\mathrm{N})$ with fine dispersed chromatin and prominent nucleolus (Nu). The cytoplasm contains RER (pink arrows), Golgi apparatus (arched arrow) and mitochondria (yellow arrowheads). Many free ribosomes (red arrow) lie between the organelles. (b) NaF-treated group showing markedly irregular nucleus $(\mathrm{N})$ with some condensation of chromatin (yellow arrows). The nucleus is surrounded by some lysosomes (notched arrows). An area of vacuolation (V) could be detected inside the cytoplasm. (c) Another section from NaF-treated group showing marked indentation (red arrow) of the nucleus (N). The cytoplasm contains slightly dilated RER (pink arrow) and some swollen vacuolated mitochondria (yellow arrowheads). (d) Protected group showing an apparently normal nerve cell having nucleus $(\mathrm{N})$ with regular nuclear outline. However, the nucleus still shows some condensation of chromatin (dashed arrow). The cytoplasm contains more or less normal mitochondria (yellow arrowheads), RER (pink arrow) and many free ribosomes (red arrow). A small area of vacuolation (V) could be still detected in the cytoplasm $(\times 4000)$. [Color figure can be viewed in the online issue, which is available at www.anatomy.org.tr]

nuclear details. Other cells showed central chromatolysis cytoplasmic hyalinization. Few cells appeared as ghostlike cells. Some blood vessels were congested and dilated. Also, some areas of vacuolation and hemorrhage and some degenerated axons with segmental disruption of myeline

Figure 23. Electrophoretographs of the cervical (a) and thoracic (b) segments of the spinal cord showing: lane 1 (negative control subgroup) showing no fragmentation of DNA, lane 2 (positive control subgroup) showing no fragmentation of DNA, lane 3 (NaF-treated group) showing severe fragmentation of DNA, and lane 4 (protected group) showing less fragmentation of DNA. (Note: $L \rightarrow 200$ bp ladder). [Color figure can be viewed in the online issue, which is available at www.anatomy.org.tr]

were observed in the neuropil. Our results were in agreement with Nour-Edien et al. ${ }^{[24]}$ and Saad El-Dien et al. ${ }^{[29]}$ who observed features of neurodegeneration in cerebellum of rats after fluoride treatment. The Purkinje cells appeared shrunken, deeply stained, with hardly identified nuclei. Few of them appeared as ghost shaped cells. They also added that $\mathrm{NaF}$ treatment led to the appearance of many vacuoles in the neuropil and some dilated and congested blood vessels. Moreover, Giri et al ${ }^{[30]}$ observed generalized congestion and hemorrhages in vital organs (i.e. liver, heart, kidney, spleen, lung and brain) of rats treated with sodium fluoride. Thangapandiyan and Milton $\mathrm{Prabu}^{[31]}$ attributed the neurodegenerative effects of fluoride to the binding of fluoride ions with antioxidant $\mathrm{N}$ acetyl-cysteine, glutathione and other free radical destroy- 
ing enzymes, triggering oxidative stress that leads to cell damage and even cell apoptosis. It was also observed that $\mathrm{NaF}$ increased nitric oxide synthase activity. This enzyme plays a major role in all neurodegenerative diseases, primarily by damaging mitochondrial energy production, inhibiting glutamate reuptake and stimulating lipid peroxidation ${ }^{[32]}$ Refsnes et al. ${ }^{[3]}$ attributed the diverse actions of fluoride to the inhibition of a variety of enzymes as metalloenzymes that were proved to be involved in many essential metabolic processes as glycolysis, oxidative phosphorylation and neurotransmission.

Dilated and congested blood vessels observed after fluoride treatment in this study were explained by Saad El-Dien et al. ${ }^{[2]}$ who stated that $\mathrm{NaF}$ affected the vascular endothelial cells leading to release of nitric oxide, which is an endothelial relaxing factor.

Afifi ${ }^{[20]}$ attributed the vacuolation observed in the neuropil to the shrinkage of cells and withdrawal of their processes secondary to cytoskeletal affection, thus leaving pericellular spaces. They also attributed the disruption in myelination after $\mathrm{NaF}$ treatment to the increased water content in degenerating nerve causing intramyelinic edema with separation of myelin lamellae.

Hemorrhage observed in the neuropil in the present study was explained by Levine ${ }^{[34]}$ who stated that fluorides react with the soluble calcium compounds in the body to form insoluble calcium fluoride and thus act as anticoagulants. So, the picture of fluoride poisoning may include hemorrhage.

In the present study, the cytoplasm of motor neurons of sodium fluoride treated rats showed an apparent decrease of Nissl's granules content and appeared faint blue in color as compared to control group. In agreement with these results, Afifi ${ }^{[20]}$ and Nour-Edien et al. ${ }^{[24]}$ observed reduction of Nissl's granules in Purkinje cells of cerebellum in $\mathrm{NaF}$-treated rats. A possible explanation for decreased Nissl's granules in NaF-treated rats is the accumulation of free radicals that led to reduction in the protein forming machinery of the neurons as mentioned by Chen et al. ${ }^{[35]}$

The neurons of NaF-treated group in this study showed positive immune reaction to caspase- 3 with dark brown staining of the cytoplasm and nuclei of these neurons. In agreement with this result, Song et al. ${ }^{[36]}$ observed positive expression of caspase- 3 and caspase- 9 proteins in liver of $\mathrm{NaF}$-treated rats. Similarly, Chen et al.$^{[35]}$ reported that fluoride exposure significantly elevated the protein expressions of caspase- 3,8 , and 9 in the kidney of the carp. They concluded that chronic exposure to fluoride leads to apoptosis through caspase-mediated pathways. Agalakova and Gusev ${ }^{[3]]}$ clarified that cas- pases are closely related family of cysteine proteases which can be divided into initiator $(-2,-8,-9,-10)$ and effector $(-3,-6,-7)$ caspases. The caspases function by a cascade, in which initiator caspases are activated by a variety of lethal stimuli. Initiator caspases then activate a set of effector caspases by their cleavage at specific target sites. The cleavage events are responsible for the most of morphological changes associated with apoptosis.

In the present study, there was an increase in the number and size of GFAP positive astrocytes in NaFtreated rats as compared to the control group. This finding was in agreement with Al-Hayani et al. ${ }^{[38]}$ who observed that GFAP positive cells were more abundant and appeared larger in the three cortical layers of cerebellum of fluoride treated rats. Similarly, Akinrinade et al. ${ }^{[39]}$ reported that fluoride administration for 30 days caused an increase in glial activation and GFAP immunoreaction of astrocytes in brain of rats. A possible explanation for increased number and size of astrocytes after central nervous system injury was mentioned by Wang et al..$^{[40]}$ who suggested that the increase of astrocytes may provide more nourishment required by the neurons. Another explanation was mentioned by Nakase et al..$^{[41]}$ who reported that increased reactive astrocytes might reduce neuronal apoptosis by regulating the concentration of potassium and neurotransmitters through gap junctions.

In the present study, electron microscopic examination of ultrathin sections from $\mathrm{NaF}$-treated rats showed neurodegenerative changes compared to controls. The nuclei appeared with irregular outline and marked condensation of chromatin. The cytoplasm contained many swollen vacuolated mitochondria with destructed cristae. The rough endoplasmic reticulum was also dilated taking a globular shape. Moreover, some areas of vacuolation could be detected inside the cytoplasm. Our results were in agreement with Afifi ${ }^{[20]}$ and Saad El-Dien et al. ${ }^{[2]}$ who reported ultrastructural changes in the form of mitochondrial swelling with disturbance in their cristae, nuclear irregularity and dilated RER cisternae in the cerebellar cortex of NaF-treated rats. Similarly, Reddy et al. ${ }^{[42]}$ observed that fluoride treatment caused irregular nuclei with vacuolated cytosol in the spinal cord and vacuolated swollen mitochondria in neocortex, hippocampus and cerebellum of fluoride treated rats.

There were many attempts to explain the ultrastructural changes that accompany $\mathrm{NaF}$ treatment. Agha et $\mathrm{al}^{\left[{ }^{[43]}\right.}$ reported that the irregular heterochromatic nuclei observed after $\mathrm{NaF}$ treatment confirmed the induction of apoptosis. Jacinto-Aleman et al. ${ }^{[4]}$ suggested that, excessive fluoride ingestion can produce DNA fragmentation resulting in apoptosis. Ge et al. ${ }^{[4]}$ attributed the 
degenerative changes of mitochondria to the mitochondrial DNA mutation. This mutation resulted in abnormal protein transcription that led to abnormal function of the mitochondria. While, Saad El-Dien et al. ${ }^{[29]}$ stated that mitochondrial alterations were due to degeneration, to stand for the high metabolic activity of the cell. Shashi ${ }^{[46]}$ reported that the main cause of the cytoplasmic vacuoles was free radicals accumulation and mutations of the genome, as the free radicals could peroxide the organelles leaving cytoplasmic vacuoles behind. Saad ElDien et al. ${ }^{[29]}$ mentioned that dilatation of RER was probably an indicator of the disturbance in the vesicular transport between it and the Golgi apparatus. Shah and Chinoy ${ }^{[4]}$ confirmed that fluoride disrupted intracellular transport from RER to Golgi apparatus.

In the present study, the apoptotic cell death in $\mathrm{NaF}-$ treated rats was confirmed genetically using agarose gel electrophoresis which revealed DNA fragmentation in spinal cord of these rats. This result was in line with Thangapandiyan and Milton $\operatorname{Prabu}^{[4]}$ who observed that $\mathrm{NaF}$ intoxicated rats showed significant increase in DNA damage. Wei et al. ${ }^{[49]}$ explained the $\mathrm{NaF}$ induced-DNA fragmentation by the emergence of an endogenous neurotoxin (3-hydroxy-kynurenine) which when present at high molecular concentration could result in chromatin condensation and internucleosomal DNA cleavage. Thangapandiyan and Milton $\mathrm{Prabu}^{[48]}$ stated that $\mathrm{NaF}$ has a dense negative charge and is biochemically very active, and thus directly affects DNA because of its strong affinity for uracil and amide bonds by the interaction of $-\mathrm{NH}$ and fluoride. Another explanation was made by Manivannan et al. ${ }^{[50]}$ who reported that $\mathrm{NaF}$ can induce the production of free radicals, which can damage DNA strands directly or by lipid peroxidation initiated by free radicals.

In the present study, addition of green tea extract to the $\mathrm{NaF}$ resulted in histological, immunohistochemical, morphometric, ultrastructural and molecular improvements. In agreement with these results, Milton Prabu and Thangapandiyan ${ }^{[51]}$ and Thangapandiyan and Milton Prabu $^{[31]}$ evaluated the protective effects of EGCG - a green tea catechin" found in a variety of green tea preparations - on $\mathrm{NaF}$ induced histological alterations in heart, liver, kidney and testes of rats. They reported that $\mathrm{NaF}$-treated groups showed marked inflammation, necrosis and degenerative changes in these organs. They added that treatment with EGCG showed marked improvement in all the degenerative changes inflicted by $\mathrm{NaF}$. Also, in line with our results, Paterniti et al. ${ }^{[52]}$ found that green tea extract treatment ameliorates spinal cord injury oxidative stress. Moreover, Renno et al. ${ }^{[53]}$ reported a significant decrease in the number of GFAP- immunoreactive astrocytes in all the spinal cord grey areas of diabetic rats treated with green tea. Jeong et al. ${ }^{[5]}$ stated that EGCG attenuates cell death and the increase in reactive oxygen species concentrations and caspase-3 activity in neuronal culture. The improvement that occurred in the protected group in spite of the administration of the same $\mathrm{NaF}$ dose used in the treated group was attributed to the antagonistic effect of green tea on the oxidative stress induced by $\mathrm{NaF}$. This was in agreement with Weinreb et al. ${ }^{[5]}$ who stated that catechins "found in green tea" possess free radical scavenging properties and act as biological antioxidants. Levites et al. ${ }^{[56]}$ explained that catechins may exert neuroprotection effects by modulation of cell survival and death genes. A low catechin concentration has been found to decrease expression of pro-apoptotic gene but with no increase of anti-apoptotic genes. Such changes are believed to increase mitochondrial integrity, which indirectly saves neurons from dying.

Another explanation for the protective effect of green tea was mentioned by Hamdy et al. ${ }^{[57]}$ who mentioned that green tea markedly normalizes the elevated nitric oxide level. Moreover, Thangapandiyan, and Milton $\mathrm{Prabu}^{[58]}$ suggested that protective effect of green tea may be due to the anti-genotoxicity of EGCG which might be due to the presence of more hydroxyl groups and more effective free radical scavengers. They added that EGCG has a potential to bind with the DNA thereby preventing the reaction of free radicals with DNA.

\section{Conclusion}

The results of this study show a protective effect of green tea against $\mathrm{NaF}$-induced neurotoxicity, add new information to the known toxic effects of $\mathrm{NaF}$, and provide a new insight into the possible use of green tea to ameliorate these effects.

\section{References}

1. Dhar V, Bhatnagar M. Physiology and toxicity of fluoride. Indian J Dent Res 2009;20:350-5.

2. Shivarajashankara YM, Shivashankara AR. Neurotoxic effects of fluoride in endemic skeletal fluorosis and in experimental chronic fluoride toxicity. Journal of Clinical and Diagnostic Research 2012;6: $740-4$.

3. Shivarajashankara YM, Shivashankara AR, Bhat PG, Rao SH. Brain lipid peroxidation and the antioxidant systems of young rats in chronic fluoride intoxication. Fluoride 2002;35:197-203.

4. Vani ML, Reddy KP. Effects of fluoride accumulation on some enzymes of brain and gastrocnemius muscle of mice. Fluoride 2000;33:17-26.

5. Shivarajashankara YM, Shivashankara AR, Bhat PG, Rao SM, Rao SH. Histological changes in the brain of young, fluoride intoxicated rats. Fluoride 2002;35:12-21. 
6. Spittle B. Fluoride fatigue. Fluoride poisoning: is fluoride in your drinking water-and from other sources-making you sick? Dunedin (NZ): Paua Press; 2009. p. 2-4.

7. Mandel SA, Amit T, Weinreb O, Youdim MB. Understanding the broad-spectrum neuroprotective action profile of green tea polyphenols in aging and neurodegenerative diseases. J Alzheimers Dis 2011;25:187-208.

8. Biasibetti R, Tramontina AC, Costa AP, Dutra MF, QuincozesSantos A, Nardin P, Bernardi, CL, Wartchow KM, Lunardi PS, Gonçalves CA. Green tea (-) epigallocatechin-3-gallate reverses oxidative stress and reduces acetylcholinesterase activity in a streptozotocin-induced model of dementia. Behav Brain Res 2013;236:18693.

9. Verma RJ, Trivedi MH, Chinoy NJ. Blake tea amelioration of sodium fluoride - induced alterations of DNA, RNA, and protein contents in the cerebral hemisphere, cerebellum and medulla oblongata regions of mouse brain. Fluoride 2007;40:7-12.

10. Carol JVF. 2012. Calculating percent increase and decrease. [Internet] Available from: http://www.onemathematicalcat.org/ algebra_book/online_problems/calc_percent_inc_dec.htm

11. Harrison RH. The nervous system. In: A laboratory manual of the anatomy of the rat. New York (NY): The Macmillan Company; 1924. p. 103-16.

12. Shen QF, Li HN, Xu TT, Xia YP. Damage of blood brain barrier of spinal cord in rats with chronic fluorosis. Chin Med J 2012;92:235761.

13. Kiernan J. Histological and histochemical methods: theory and practice. 3rd ed. Oxford: Hodder Arnold Publishers; 1999. p. 94.

14. Horobin RW, Bancroft JD. Troubleshooting histology stains. London: Churchill Livingstone; 1998. p. 88-93.

15. Sternbergcr L. Immunocytochemistry. 3rd ed. New York (NY): John Wiley; 1986. p. 190-209.

16. Bancroft JD, Gamble M. Theory and practice of histological techniques. 5th ed. London: Churchill Livingstone; 2002. p. 373.

17. Al-Gholam MA, Elbarbary AA, Zolfakar AS, Nooh HZ, El-Mehi $\mathrm{AE}$. The role of rosemary on acrylamide neurotoxicity during postnatal development of rat spinal cord: histological, immunohistochemical and genetic study. MD thesis. Department of Anatomy and Embryology, Faculty of Medicine, Menoufia University, $\mathrm{Al}$ Minufiyah, Egypt; 2015. p. 197.

18. Soliman, N, Abdel Tawab S, Nada H., Mohammed S. Histological and immunohistochemical study of the effect of hypo and hypercaloric diet on the structure of aorta and hippocampus of male albino rat. MD thesis. Department of Histology, Ain Shams University, Cairo, Egypt; 2006. p. 40-2.

19. De Muth JE. Basic statistics and pharmaceutical statistical applications. 3rd ed. New York (NY): CRC Press; 2014. p. 95-61.

20. Afifi OK. Effect of sodium fluoride on the cerebellar cortex of adult albino rats and the possible protective role of vitamin B6: a light and electron microscopic study. The Egyptian Journal of Histology 2009;32:358-67.

21. Hamid S, Kawoosa, Z, Hamid S, Mir MA, Hafiz A, Jan I, Yaqoob F. Histopathological effects of varied fluoride concentration on cerebrum in albino rats. Journal of Interdisciplinary Histopathology 2012;1:30-4.

22. Reddy PY, Reddy KP, Kumar KP. Neurodegenerative changes in different regions of brain, spinal cord and sciatic nerve of rats treated with sodium fluoride. Journal of Medical and Allied Sciences 2011;1:30-5.
23. Trivedi MH, Verma RJ, Sangai NP, Chinoy NJ. Mitigation by black tea extract of sodium fluoride induced histopathological changes in brain of mice. Fluoride 2012;45:13-26.

24. Nour-Edien NM, Mansour FK, El-Safti F, El-Habiby MM, El-Fiky MM. Histological and immunohistochemical studies on the effect of sodium fluoride on postnatal development of the cerebellum in rat. MD thesis. Department of Anatomy and Embryology, Faculty of Medicine, Menoufia University, Al Minufiyah, Egypt; 2007. p.194-212.

25. Mitchell WA. Fluoride: friend or foe? 2000. Part 3. [Internet] Available from: http://paradisecafediscussions.org/forum/showthread. php? mode=linear\&tid=1089\&pid $=13213$

26. Lu C, Zhu W, Shen CL, Gao W. Green tea polyphenols reduce body weight in rats by modulating obesity-related genes. PLoS One 2012;7:e38332.

27. Farooqui AA. Phytochemicals, signal transduction, and neurological disorders. New York (NY): Springer; 2012. Chapter 5, Beneficial and side effects of green tea chatechines. p. 117-50.

28. Cooper R, Morré DJ, Morré DM. Medicinal benefits of green tea: Part I. Review of noncancer health benefits. J Altern Complement Med 2005;11:521-8.

29. Saad El-Dien, HM, El Gamal DA, Mubarak HA, Saleh SM. Effect of fluoride on rat cerebellar cortex: light and electron microscopic studies. The Egyptian Journal of Histology 2010;33:245-56.

30. Giri DK, Ghosh RC, Mondal M. Pathology of acute oral toxicity of sodium fluoride in Wistar rats. Indian Journal of Veterinary Pathology 2014;38:33-8.

31. Thangapandiyan S, Milton Prabu S. Molecular mechanism of fluoride induced oxidative stress and its possible reversal by chelation therapy. Research \& Reviews: A Journal of Toxicology (RRJoT) 2013;3(2):1-11.

32. Nasir N, Asad MR. Effects of fluoride on CA3 region of hippocampus in adult albino rats. Journal of Asian Scientific Research 2013;3:729-33.

33. Refsnes M, Thrane EV, Lag M, Hege TG, Schwarze PE. Mechanisms in fluoride-induced interleukin- 8 synthesis in human lung epithelial cells. Toxicology 2001;167:145-58.

34. Levine VE. Acids and alkalies: In: Stewart CP, Stolman A, editors. Toxicology: mechanisms and analytical methods. New York (NY): Academic Press; 1961. p. 597-636.

35. Chen J, Chen X, Yang K, Xia T, Xie H. Studies on DNA damage and apoptosis in rat brain induced by fluoride. [Article in Chinese] Zhonghua Yu Fang Yi Xue Za Zhi 2002;36:222-4.

36. Song GH, Huang FB, Gao JP, Liu ML, Pang WB, Bin LW, Yan XY, Huo MJ, Yang X. Effects of fluoride on DNA damage and caspase-mediated apoptosis in the liver of rats. Biol Trace Elem Res 2015;166:173-82.

37. Agalakova NI, Gusev GP. Molecular mechanisms of cytotoxicity and apoptosis induced by inorganic fluoride. ISRN Cell Biology 2012;403835:1-16.

38. Al-Hayani A, Elshal EB, Abdel IAH, Al-Shammeri E. Does vitamin E protect against sodium fluoride toxicity on the cerebellar cortex of albino rats? Middle-East Journal of Scientific Research 2013;16: 1019-26.

39. Akinrinade ID, Memudu AE, Ogundele OM, Ajetunmobi OI. Interplay of glia activation and oxidative stress formation in fluoride and aluminium exposure. Pathophysiology 2015;22:39-48. 
40. Wang X, Xu Y, Wang F, Tang L, Liu Z, Li H, Liu S. Aging-related changes of microglia and astrocytes in hypothalamus after intraperitoneal injection of hypertonic saline in rats. J Huazhong Univ Sci Technolog Med Sci 2006;26:231-4.

41. Nakase T, Fushiki S, Naus CC. Astrocytic gap junctions composed of connexin 43 reduce apoptotic neuronal damage in cerebral ischemia. Stroke 2003;34:1987-93.

42. Reddy PY, Reddy KP, Kumar KP. Neurodegenerative changes in different regions of brain, spinal cord and sciatic nerve of rats treated with sodium fluoride. Journal of Medical and Allied Sciences 2011;1:30-5.

43. Agha FE, El-Badry MO, Hassan DAA, Abdelraouf AA. Role of vitamin $\mathrm{E}$ in combination with methionine and l-carnosine against sodium fluoride -induced hematological, biochemical, DNA damage, histological and immunohistochemical changes in pancreas of albino rats. Life Science Journal 2012;9:1260 -75.

44. Jacinto-Alemán LF, Hernández-Guerrero JC, Trejo-Solís C, Jiménez-Farfán MD, Fernández-Presas AM. In vitro effect of sodium fluoride on antioxidative enzymes and apoptosis during murine odontogenesis. J Oral Pathol Med 2010;39:709-14.

45. Ge Y, Ning H, Wang S, Wang J, Effects of high fluoride and low iodine on the histopathology of brain in offspring rats. Fluoride 2005;38:127-32.

46. Shashi A. Histopathological investigation of the fluoride-induced neurotoxicity in rabbits. Fluoride 2003;36:95-105.

47. Shah SD, Chinoy NJ. Adverse effects of fluoride and/or arsenic on the cerebral hemisphere of mice and recovery by some antidotes. Fluoride 2004;37:162-71.

48. Thangapandiyan S, Milton Prabu S. Epigallocatechin gallate potentially ameliorates sodium fluoride-induced genotoxicity in rats. Asian Journal of Pharmacology and Toxicology 2013;;1:8-16.

49. Wei H, Leeds P, Chen RW, Wei W, Leng, Y, Bredesen, DE, Chuang DM. Neuronal apoptosis induced by pharmacological concentrations of 3-hydroxykynurenine: characterization and protection by dantrolene and Bcl-2 overexpression. J Neurochem 2000;75:81- 90.
50. Manivannan J, Sinha S, Ghosh M, Mukherjee A. Evaluation of multiendpoint assay to detect genotoxicity and oxidative stress in mice exposed to sodium fluoride. Mutat Res 2013; 751:59-65.

51. Miltonprabu S, Thangapandiyan S. Epigallocatechin gallate potentially attenuates fluoride induced oxidative stress mediated cardiotoxicity and dyslipidemia in rats. J Trace Elem Med Biol 2015;29:321-35.

52. Paterniti I, Genovese T, Crisafulli C, Mazzon E, Di Paola R, Galuppo M, Bramanti P, Cuzzocrea S. Treatment with green tea extract attenuates secondary inflammatory response in an experimental model of spinal cord trauma. Naunyn Schmiedebergs Arch Pharmacol 2009;380:179-92.

53. Renno WM, Alkhalaf M, Afsari Z, Abd-El-Basset E, Mousa A. Consumption of green tea alters glial fibriliary acidic protein immunoreactivity in the spinal cord astrocytes of STZ-diabetic rats. Nutr Neurosci 2008;11:32-40.

54. Jeong JH, Kim HJ, Lee TJ, Kim MK, Park ES, Choi BS. Epigallocatechin 3-gallate attenuates neuronal damage induced by 3hydroxykynurenine. Toxicology 2004;195:53-60.

55. Weinreb O, Amit T, Mandel S, Youdim MB. Neuroprotective molecular mechanisms of (-)-epigallocatechin-3-gallate: a reflective outcome of its antioxidant, iron chelating and neuritogenic properties. Genes Nutr 2009;4:283-96.

56. Levites Y, Amit T, Youdim, MB, Mandel S. Involvement of protein kinase $\mathrm{C}$ activation and cell survival/cell cycle genes in green tea polyphenol (-)-epigallocatechin 3-gallate neuroprotective action. J Biol Chem 2002;277: 30574-80.

57. Hamdy MA, El-Maraghy SA, Kortam MA. Modulatory effects of curcumin and green tea extract against experimentally induced pulmonary fibrosis: a comparison with $\mathrm{N}$-acetyl cysteine. J Biochem Mol Toxicol 2012;26:461-8.

58. Thangapandiyan S, Milton Prabu S. Protective effect of epigallocatechin gallate (EGCG) on sodium fluoride (NaF) induced changes in histology of selected organs in rats. Research \& Reviews: A Journal of Toxicology (RRJoT) 2013;3(1):1.

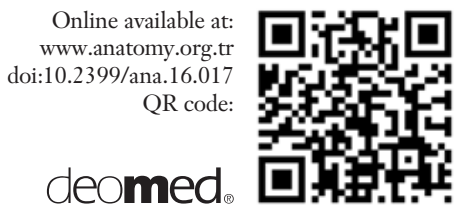

Correspondence to: Doaa M. Abo El-Khair, MD

Department of Anatomy and Embryology, Faculty of Medicine,

Menoufia University, Al Minufiyah, Egypt

Phone: +201005651390

e-mail: neveensherif@yahoo.com

Conflict of interest statement: No conflicts declared.

This is an open access article distributed under the terms of the Creative Commons Attribution-NonCommercial-NoDerivs 3.0 Unported (CC BY-NCND3.0) Licence (http://creativecommons.org/licenses/by-nc-nd/3.0/) which permits unrestricted noncommercial use, distribution, and reproduction in any medium, provided the original work is properly cited. Please cite this article as: Abo El-Khair DM, El-Safti FEA, El-Habeby MM, El-Kholy WB, El-Sherif NM. Effect of sodium fluoride on the grey matter of spinal cord in the albino rat and the protective role of green tea extract. Anatomy 2016;10(2):114-133. 